\title{
Information and Persuasion: Achieving Safe Water Behaviors in Kenya
}

\author{
Jill Luoto* \\ JOB MARKET PAPER
}

August 2009

\begin{abstract}
This paper considers the disappointing adoption rates of point-of-use (POU) safe water technologies designed to expand access to safe drinking water in the developing world. Low cost POU technologies substantially reduce diarrheal disease (Clasen et al. 2006). Nevertheless, they remain little used in many parts of the developing world, even when widely available. I present results from a randomized field study in Kenya that provided for free a variety of POU technologies in order to test hypothesized informational and behavioral constraints to the widespread use of any POU safe water technology. Sharing water quality information increases water treatment by $8-13$ percentage points, representing a $12-23 \%$ increase over base values. Framing safe water technologies as both increasing health and avoiding disease (not just increasing health) further increased usage on the order of 4-6 percentage points. A public commitment by respondents to treat water regularly had weak but positive effects overall, but large effects at households that showed "present-biased" responses to hypothetical questions about future payoffs. These results suggest promising avenues for incremental improvements in the market for safe water (and other) technologies. More broadly, they present further evidence against a model of decision making that assumes full information and fully formed preferences. JEL CODES: M31, O33, D81, D83, Q53, D91.
\end{abstract}

${ }^{*}$ Department of Agricultural and Resource Economics, University of California, Berkeley. This research was supported by the Blum Center for Developing Economies and the P\&G Fund of the Greater Cincinnati Foundation, and conducted as part of a larger research effort in partnership with Jeff Albert of The Aquaya Institute, David Levine of UC-Berkeley Haas School of Business, and CARE-Kenya. It has benefitted from conversations with members of the Kenya Rural Water Project in nearby Busia, Kenya, along with seminar participants at UC Berkeley. Many thanks to Davis Ochieng, Salome Aoko, Emeldah Orowe, George Wambiya, Maureen Mbolo and Susan Leah Osanjo for excellent field data collection, as well as to Brad Lang, Sam Ombeki and Gordon Oluoch for management assistance. All errors are my own. 


\section{Introduction}

Many promising technologies intended to help break the cycle of poverty fail to realize their full benefits in practice. Whether it is preventing the spread of sexually transmitted disease through the use of condoms, or increasing crop yields through the use of fertilizer, when the decision to adopt a technology is left to individuals, actual benefits often fall short of potential benefits.

The most obvious barrier to the adoption of such private good technologies is income: Poor households cannot afford to purchase a technology to help lift them out of poverty, and so poverty begets more poverty. However, the decisions to purchase and use a technology are distinct from each other, and only the latter delivers the intended benefits. If people lack a clear understanding of the benefits posed by use of a technology, if they are present-biased or simply find a technology unappealing, adoption may remain low even when provided for free. Thus the behavior of private individuals who are subject to many behavioral biases and informational constraints also underlies the adoption decision.

This paper considers the disappointing adoption rates of point-of-use (POU) safe water technologies to expand access to safe drinking water in the developing world. Diarrhea is the second ${ }^{1}$ leading cause of under-five mortality worldwide, killing two million children in poor countries every year; inadequate access to safe water is a primary cause (Zwane and Kremer 2007). Efforts to lessen diarrhea's impact include the development of many low-cost technologies that improve drinking water at the point of use (generally the household). Such POU measures range from solar disinfectant practices, filters and UV irradiation devices (where electricity is available) to disinfectants such as chlorine solution and tablets, as well as flocculant/disinfectant mixtures. A number of randomized controlled studies have shown that such low-cost POU drinking water treatment measures can substantially reduce diarrheal incidence (Clasen, Roberts, Rabie, Schmidt and Cairncross 2006). As a result, POU technologies have gained favor among epidemiologists and public health specialists as a low-cost and effective solution to the challenge of rapidly expanding access to potable drinking water to the 1.1 billion people who lack access to safe drinking water sources (Harris 2005). Yet adoption rates of POU technologies remain low in many parts of the world. The research frontier is now shifting from documenting the efficacy of each technology to understanding consumer's decisions to adopt and use any safe water technology. While cost remains an obstacle, a larger obstacle appears to be achieving change in people's daily water-related behaviors (Zwane and Kremer 2007, Luby, Mendoza, Keswick, Chiller and Hoekstra 2008).

This paper hypothesizes some possible constraints to widespread and sustained POU adoption

\footnotetext{
${ }^{1}$ Excluding neonatal causes.
} 
and it presents results from a field experiment conducted in rural western Kenya that aimed to test such hypothesized constraints. In our study area in Kenya we found a paradox that has been noted anecdotally elsewhere: People expressed concern about diarrhea, yet almost no households used POU products despite widespread familiarity with and availability of POU products. ${ }^{2}$ Rates of reported water boiling were also low, suggesting the market cost of POU products alone may not be the only deterrent to their adoption. ${ }^{3}$ There appears to be a missing link between concern for diarrhea and taking action to prevent it.

The goal of this paper is to explore potential causes for this missing link. As such, our outcomes of interest will be measures of usage of safe water products. We do not directly collect corresponding measures of health. Rather, we rely on findings from numerous existing field studies from the epidemiological and public health fields that have shown that POU measures are effective at cleaning drinking water and therein reducing diarrheal incidence (Clasen et al. 2006); clean drinking water reduces diarrheal incidence significantly (Zwane and Kremer 2007); and reductions in diarrheal episodes lead to positive health outcomes, particularly for children under five (Jones, Steketee, Black, Bhutta, Morris and the Bellagio Child Survival Study Group 2003). ${ }^{4}$ From this starting point, we consider why adoption rates of POU products are low despite their effectiveness, low cost, and the magnitude of the problem they are intended to address.

We hypothesized that individuals may (1) be too poor to purchase a POU product; (2) lack complete information about the link between contaminated water and disease; (3) have non-standard preferences over time and suffer from self-control problems; (4) make decisions using commonly utilized heuristics instead of solving complex decision problems as perfectly rational economic agents. Our field experiment alleviated any budget constraints by providing all participating households with free POU products. This allows us to put aside hypothesis (1) in order to consider hypotheses (2)-(4) and the roles played by informational and behavioral constraints on the POU

\footnotetext{
${ }^{2}$ At the baseline interview, a majority (55\%) of respondents freely named diarrhea in their list of the three most problematic diseases affecting their district, yet just 29 of 400 households self-reported current POU usage despite the fact that $98 \%$ of respondents had heard of at least one POU product, and POU products are widely available in the area (and subsidized in order to make them "affordable").

${ }^{3}$ Boiling can be an effective means of water purification and can be considered as a substitute for POU product treatment. Costs of boiling include either the costs of fuel or the time costs of firewood collection and associated deforestation.

${ }^{4}$ Besides death, risks of diarrheal illness include dehydration and malnutrition, which in turn can lead to diarrhea in a negative cycle. One estimate is that $25 \%$ of the growth differential between children in developing and developed countries is due to diarrhea ((Black, Brown and Becker 1984) as cited in (Mirza, Caulfield, Black and Macharla 1997)). Furthermore, diarrheal episodes can imply missed days of school or work for the ill and their caretakers.
} 
usage (i.e., post-“purchase") decision. ${ }^{56}$

If households lack full information about their water quality or the link between contaminated water and disease, then their POU adoption choices may not reflect their true preferences over safe water and health. Incomplete information about the benefits of a technology or the problem it is intended to address has been found to slow the adoption of a variety of technologies including fertilizer (Foster and Rosenzweig 1995, Duflo, Kremer and Robinson 2007), and condoms (Adetunji and Meekers 2001). Our experiment tested hypothesis (2) and the role of information by providing randomly selected households with the results of water quality tests.

Providing information about water quality has increased the likelihood of households adopting safe water behaviors in other settings (Madajewicz, Pfaff, van Geen, Graziano, Hussein, Momotaj, Sylvi and Ahsan. 2007, Jalan and Somanathan 2008). Our test of the role of information is unique in that we allow for the possibility that the provision of information is not only expanding people's information sets per se (hypothesis (2)), but is adding salience to a problem that is already at least partly understood (hypothesis (4)). We attempt to disentangle these two channels by testing if the type of information provided matters: Some households were provided results from common water source collection points while others were provided both source water results and results from their own private in-home stored water supplies. In a neoclassical world the additional personalized information should not matter if both tests show contamination; the provision of common source results should provide any missing information. In practice, attention is a limited resource (DellaVigna 2009), and people often use an "availability heuristic" to weight personal experience more heavily in decisions involving a variety of self-protective behaviors (Simonsohn, Karsson, Loewenstein and Ariely 2008). ${ }^{7}$ We therefore predicted that the personalized results may further increase usage by adding salience to this information.

To test hypotheses (3)-(4), our study randomly assigned marketing messages designed to appeal to well known psychological heuristics. There is a wide body of evidence that important real world decisions can be affected by how those decisions are presented, even when the content of a choice set has not changed (Cialdini 1993). While the importance of such deviations from a neo-

\footnotetext{
${ }^{5} \mathrm{~A}$ companion paper to this one presents results from pitting different $\mathrm{POU}$ products against each other to determine the role of product design. Since all POU products are designed to deliver safe drinking water, we focus here on the common decision-making barriers to the adoption of any POU treatment measure.

${ }^{6}$ The role of charging positive prices for private POU products has been explored elsewhere in Ashraf, Berry and Shapiro (2007), where the authors find charging a positive price screens out non-users of a chlorine product in urban Zambia, while Kremer, Miguel, Mullainathan, Null and Zwane (2009) argue that charging any price drastically cuts demand in nearby Busia, Kenya.

${ }^{7}$ The availability heuristic can be explained intuitively as "the impact of seeing a house burning on the subjective probability of such accidents is probably greater than the impact of reading about a fire in the local paper" (Tversky and Kahneman, 1974 p. 1127).
} 
classical model of behavior is still under debate (DellaVigna 2009), there is increasing consensus that consumers respond to noninformative content in marketing and advertising (Bertrand, Karlan, Mullainathan, Shafir and Zinman 2009). And although some POU products have enjoyed extensive social marketing campaigns in many countries, the effectiveness of marketing campaigns that attempt to harness such behavioral biases in favor of the adoption of POU products has not been extensively explored. ${ }^{8}$ More generally, given the low rates of sustained adoption for POU products throughout much of the developing world, it is safe to conclude that a viable marketing campaign that successfully persuades individuals to change their behavior remains elusive.

If people suffer from self-control problems and place disproportionate weight on the present period at the expense of all future periods, the investment good nature of POU products (they require effort to use today but health benefits are not enjoyed until tomorrow) could be another hindrance to their consistent usage. Our field study addressed this with a randomized public "commitment" treatment that asks one half of participating households to promise aloud to use their POU product. Psychological research has shown that committing oneself to a behavior today can be an effective means of altering one's future behavior (Cialdini 1993). We attempt to harness this psychological tenet in favor of the adoption of POU products.

Finally, prospect theory predicts that fear appeals might be a more effective means of encouraging POU usage due to loss aversion, but social marketers argue strongly for aspirational messages that emphasize the positive aspects of usage (PSI 2007). The way a decision is framed can have large effects on people's choices by altering their "reference points" (Tversky and Kahneman 1981). Our experiment tests for "framing effects" by randomly assigning households to receive marketing messages that emphasize what they stand to gain from use of a POU product or what they stand to lose from not using a POU product.

We find positive roles both for information and our psychological appeals on increasing POU adoption rates. In particular, the sharing of common source water quality information results in an 8-13 percentage point rise in rates of POU adoption, representing a 12-23\% increase over base values. The sharing of personalized water quality information does not further increase POU usage. Although we initially hypothesized that the personalized information would add salience while the source results would provide "full information," we offer suggestive evidence that about half of the realized information effects operated via the channel of adding salience to a known problem instead of uncovering an unknown one. We also find framing safe water technologies as increasing health and avoiding disease (not just increasing health) further increased adoption rates on the

\footnotetext{
${ }^{8}$ An exception is Kremer et al. (2009), who explore the ability of various intensive social marketing campaigns to induce greater adoption of a chlorine product in Busia, Kenya. More details comparing our study with theirs are given in section 2 .
} 
order of 4-6 percentage points. Publicly committing to water treatment realizes positive but weak effects overall, but much larger effects when we consider just those households we label "presentbiased" based on responses to a hypothetical question about future payoffs, i.e., those households we would predict to be the earliest to fall out of the behavior of water treatment over time. Finally, we find that despite attempting to address a variety of possible constraints to widespread adoption, there are limits to what can be achieved through free product provision, psychological manipulations, information provision, and even changes in product design: We never approach $100 \%$ coverage. If universal access to safe drinking water is a policy objective, this casts doubt on the ability of POU products to achieve this goal. If the goal is market viability of these private health products, these results suggest promising avenues for small but measurable improvements. Many of these interventions are potentially cost-effective and necessitate only a rethinking of already existent marketing strategies. They also contribute to the growing economics literature on the shortcomings of a decision making model that assumes full information and fully formed, and consistent, preferences.

The rest of this paper proceeds as follows. Section 2 describes the field setting and study design we implemented to test the roles of information and marketing appeals in achieving adoption of POU products. It then outlines the behavioral theories underlying the precise information and marketing appeals implemented, and describes how they were implemented. Section 3 describes the data collected. Section 4 presents results, and section 5 concludes.

\section{Study Design Overview}

\subsection{Background}

We partnered with the non-governmental organization (NGO) CARE-Kenya to carry out a field study from July 2008 to February 2009 of 400 randomly selected households in 28 villages located within the Nyawita sublocation of Nyanza province, rural western Kenya. This part of Kenya is among Kenya's poorest regions and was chosen due to the area's seasonal reliance for drinking water on turbid earthpans, which are naturally occurring pools of surface water that often dry up between rainy seasons. Drinking water conditions vary tremendously throughout the year in this part of Kenya, but rainwater collection and reliance on public taps are favored options when available. Other available types of water sources include the Yala river that borders one side of Nyawita and the various earthpans that dot the landscape.

This part of Kenya is predominantly Luo, one of the larger tribes in Kenya, and Luo tradition 
dictates many water behaviors. In particular, Luo culture forbids hoarding water, and thus the various taps that are scattered throughout Nyawita are effectively public property even if located within a family's private compound. However, the taps do not always function and are prone to break down and/or have long waiting lines. This means that when a woman collects drinking water for her family (which is general practice in this area), her decision for where to collect water is likely to be a function of expected collection time, and distance and expected water quality from the various available sources. All of these decision variables in turn will depend on the season. Furthermore, because of the potentially long distances one must travel to a water point, Luo women often collect more water in a single trip than can be stored in a single container (for washing, cleaning, and drinking). Some collected water is immediately earmarked as drinking water while other water remains for any use and only becomes drinking water once added to the family's designated drinking pot.

Rainfall patterns in Nyawita follow a bimodal distribution, with monthly average peaks of $\sim 160 \mathrm{~mm}$ occurring in April and August, respectively. May-August constitutes a moderately dry period with monthly rains of $\sim 100 \mathrm{~mm}$ in June. From September onward, precipitation drops steeply, with monthly average rains of less than $40 \mathrm{~mm}$ in January (Kenya Agricultural Research Institute (KARI) n.d.).

At the baseline interview in July and August 2008, comprising the tail end of the long rainy season when one might expect better than average water quality, $86 \%$ of all household stored baseline water samples from all source types (rain water, tap water, earthpan water, river water) tested positive for E. coli, an indicator of fecal contamination. WHO international drinking water standards recognize the presence of any E. coli in drinking water to constitute a nonzero risk of waterborne disease.

The high rates of water contamination in Nyawita are matched by high rates of diarrhea. At baseline, $42 \%$ (169 of 400) of homes reported a child under 5 had diarrhea in the preceding two weeks. Despite its prevalence, it is unclear if households are sufficiently informed about the causes of diarrhea. Nearly half (49\%) of homes failed to name "drink clean water" when asked ways to prevent diarrhea. ${ }^{9}$ It is also possible that households are informed yet adopt an apathetic attitude towards diarrhea prevention: Just 18\% (71 of 400) of homes report consistent boiling of their drinking water (despite $58 \%$ of homes being able to name "boil drinking water" as another method of diarrhea prevention), and only $7 \%$ of homes (29 of 400) reported their current drinking water as being treated by another POU method despite that $98 \%$ of homes had heard of at least one POU

\footnotetext{
${ }^{9}$ This question was asked as an open response and enumerators prompted respondents three times without suggesting answers. More details and possible responses are listed in footnote 26.
} 
method. POU treatment was verified (by a positive chlorine test) in just 6 of 400 homes (1.5\%).

The low POU adoption rates despite high rates of water contamination and diarrhea prevalence in this setting is similar to that found in Kremer et al. (2009) in nearby Busia, Kenya. However, Nyawita has effectively no naturally occurring springs, while in Busia springs are a primary water source type for households. We further compare our study with theirs when we discuss our persuasive appeals in subsection 2.4 .

\subsection{Experimental Design}

Our field experiment began at the tail end of the long rainy season in July-August 2008 when enumerators visited 400 randomly selected compounds (a collection of households; Luo tradition allows for polygamous marriages) across the 28 villages comprising Nyawita. The sole selection criterion for inclusion in the study was presence of a child under five in the compound. Enumerators requested to speak with the mother of the youngest child in the compound to conduct a baseline interview of present water and hygiene knowledge and behaviors, as well as prior exposure to any POU technologies. Enumerators then gave detailed presentations on three different POU measures in randomized order: a liquid chlorine product branded as WaterGuard, Procter \& Gamble's flocculant-disinfectant powder branded as Pur, and porous ceramic filters.

After the product introductions, respondents were exposed to a randomly assigned "framed" message. The framing messages were implemented orthogonally to the order of product introductions, and were intended to test the ability of framing effects to influence adoption of any safe water behavior and not relative preferences between the three POU products. In particular, one half of households were randomly assigned to hear a "positively framed" message that emphasized only the gains from POU usage, while the other half of households were given a "contrast" frame that contrasted what one stands to lose from non-adoption with the gains from POU usage.

At the end of the baseline interview, respondents were randomly assigned one of the three POU technologies for a two month trial. At this point, orthogonal to the framing treatment and the assigned product, a randomly assigned half of households was asked to verbally commit to use their assigned POU product.

Two months later, all households were revisited to ask about updated preferences for the POU products, redeliver all marketing (framing and commitment) treatments, and measure water quality in stored untreated and treated water in order to verify product usage. The same marketing messages were given to households at all subsequent visits in the hope that successive messages would reinforce earlier ones. At this point, respondents were cycled through (in random fashion) one of the remaining POU products for a new two month trial. This process was repeated until 
every participant had the opportunity to experience all 3 POU products, each for two months, in random order.

In addition to all of these randomized treatments at the household level, our study randomly shared information about water quality at the village level. This was done to minimize any leakage of effects across households between survey rounds. The information treatments were administered as follows. At the first follow-up visit two months after the baseline interview, households in one third of villages were provided with information about the quality of their common source drinking water collection points. Households in a separate third of villages were provided information about the quality of their common source, as well as private household, drinking water supplies based on tests performed two months previously during the baseline interview. A final third of households was not provided the results of any water quality tests during this visit. At the second follow-up visit 4 months after the baseline interview, villages were staggered into "full treatment" as follows. Households in villages that received only source water results two months previously now also received results of water quality tests performed on their own stored supplies, ${ }^{10}$ while the households that did not receive any information were now provided the results of source water quality tests. Information about water quality was communicated as either a "contaminated" or "not contaminated" result, i.e., there was no discussion about levels of contamination.

In between each two month product cycle, a randomly selected subset of 100 households was subjected to an unannounced, 5-minute "spot check." These spot checks were intended to observe usage patterns at lengths of product exposure less than the full two month cycles as well as to check on POU product performance. A complete time-line of data collection activities can be found in Figure 1. The final exit survey was conducted in January and February, 2009, at the peak of the long dry season on the 370 households that completed the study. ${ }^{11}$

\subsection{The Three POU Products}

All of the included POU products have been tested in numerous randomized controlled field trials and shown to significantly reduce contamination in drinking water in a variety of settings. The ran-

\footnotetext{
${ }^{10}$ At this visit, water quality test results shared were from the two month mark of the study, unless tests showed contamination despite the household reporting use of their POU product. If this was the case, households were provided with the water quality results from the baseline round and this was made clear to respondents. This was done to avoid biasing true users of the products against a product that was performing at less than $100 \%$ effectiveness (all products perform at greater than zero effectiveness, but it is possible that a product reduces only $99 \%$ of contamination instead of $100 \%$, for example).

${ }^{11}$ This results in an overall retention rate of $92.5 \%$. The most commonly cited reason for a household to drop out of the study was migration to an urban area. More details on attrition during the study can be found in section 3 when we describe the collected data.
} 
domized order of product assignments was achieved by printing the product assignments directly into surveys and preassigning surveys to households. Compliance was easy to observe since enumerators had to carry the assigned product and associated supplies to an interview. All products were distributed along with covered buckets and taps in order to enable safe storage. Although this paper's focus is on the common behavioral and informational barriers to the adoption of any POU treatment method, the interested reader is referred to the Appendix for brief introductions to the three included POU products of WaterGuard, Pur and a filter.

\subsection{Persuasion Interventions}

Although it is generally accepted that marketing can influence consumer demand for a product's purchase, there is less evidence that marketing can induce behavior change after a product has been purchased or adopted. Ultimately, the ability of marketers to get POU products off the shelves of suppliers will not deliver any health benefits. Only after a private decision by households to use these products is made can health benefits accrue. Moreover, only with sustained usage can a successful business model develop for private health products of a consumable nature. This study explored the ability of utilizing well known psychological heuristics to affect household behavior with respect to actual product usage.

Our study is not the first to test the ability of marketing messages to affect behavior. Bertrand et al. (2009) find that mailed fliers that include randomized advertising content appealing to different psychological heuristics can affect the take-up of loans in South Africa. Agarwal and Ambrose (2008) find that randomly assigned direct mail solicitations influenced consumers' choices of financial contracts in the US home mortgage market. In the context of POU safe water adoption, Kremer et al. (2009) also test the ability of intensive social marketing appeals to induce greater adoption of WaterGuard in a nearby area of Kenya. They conclude that social marketing alone does not hold much promise of promoting widespread adoption. However, ours is the first study to expressly design and test marketing appeals that attempt to harness behavioral anomalies to increase POU adoption rates. Furthermore, we have additional measures of usage that avoid some of the problems with their measures (self-reports and chlorine residual).

The design of our study is such that outcomes are measured two months following treatment at a successive interview (or at shorter intervals for the subset of homes that received a spot check). Thus, for the persuasive appeals and information treatments to have measurable effects on behavior, they must affect behavior two months following treatment. We argue this is a relatively stringent test of these persuasive and informational interventions, but it is also the correct test from the viewpoint of achieving medium-term behavioral change. If such tactics can be harnessed in a 
predictable way to encourage water treatment behavior change, then a potentially powerful tool could be at the disposal of marketers, producers, NGOs, and governments alike. The choices of what decision-making heuristics to test were drawn from the psychology literature on persuasive communication.

\section{Framing}

The principle of invariance underlying the rational theory of choice suggests that the ordering of people's preferences should not be affected by alternative descriptions of a problem. In practice, the way a decision is framed can have large effects on people's choices by altering their "reference points," even when the underlying logic of a decision has not changed (Tversky and Kahneman 1981, Rabin 1998, Block and Keller 1995, Smith and Petty 1996, Bertrand et al. 2009). With respect to POU adoption, we test the relative merits of emphasizing what is to be gained from usage of a POU product, with what could be lost from not using a safe water technology. There are competing hypotheses in the literature for whether framing POU adoption as a gain or a loss should bring about the larger response. Prospect theory predicts that loss aversion will cause the loss-framed message to realize a bigger effect on people's choices and behavior (Tversky and Kahneman 1981, Kahneman and Tversky 1979). However, there is evidence that decisions regarding health behaviors respond more to gain-framed messages when the promoted health behavior is of a preventative nature (such as water treatment), while loss-framed messages are more effective at promoting detection behaviors (such as breast self examinations) (Rothman, Martino, Bedell, Detweiler and Salovey 1999). This is hypothesized to be due to people's perceptions of detection behaviors as risky with uncertain outcomes and are risk-seeking over loss-framed information, while people are risk-averse over prevention behaviors to maintain current health status and therein respond more to gain-framed information. Population Services International (PSI), an NGO that handles marketing and product distribution for both WaterGuard and Pur in Kenya as well as 20 other countries, has published a social marketing "best practices" manual that argues strongly in favor of a positively framed message. In it they write:

"Branded campaigns need to be aspirational; that is, consumers need to be inspired by the images and messages they see and hear and then aspire to create the same images in their homes. To create the aspiration, branded campaigns need to focus on the positive attributes of using the safe water solution. To get across the notion that the product can help protect children's health, campaigns must convey images of happy, healthy families that successfully use the product" (PSI 2007, p.28). 
In place of a negative-only framed message, we utilized a "contrast" frame that combined both negative and positive images and messages. This was done both to satisfy our implementing partner CARE as well as to avoid making respondents feel truly hopeless. There is evidence in the persuasive communication literature that framing the problem as a loss, and then presenting a solution with emphasis on the individual's ability to achieve this solution in a positive frame, can be a powerful formula for inducing behavior change (Gass and Seiter 2007). We tested for this in the context of POU product adoption.

To implement this randomization, households assigned to hear the positive frame were exposed to a marketing appeal that included the showing of images of happy, smiling children and a "clean" glass of water as the enumerator read to the respondent a few sentences about what they stand to gain from regular use of a safe water product. The other half of households was exposed to a marketing appeal that contrasted photographs of a sad, crying child and a visibly dirty glass of water next to a happy, smiling child with a "clean" glass of water. The corresponding verbal script read by survey enumerators began by emphasizing that the sad, crying child had diarrhea due to drinking contaminated water. It then became the exact same as the positively framed message to emphasize what the respondent stands to gain from regular use of a safe water product: clean water and a happy, smiling child. ${ }^{12}$

Our priors on expected effects of this treatment were in favor of the contrast frame inducing a greater response. Figure 2 explains our intuition by drawing on prospect theory's hypothetical value function of Kahneman and Tversky (1979). In prospect theory, individuals are hypothesized to make decisions based on relative changes from a reference point such as current health or wealth instead of over final utility states as assumed by expected utility theory. Furthermore, in prospect theory losses are weighted more heavily than gains, which causes the S-shaped value function in Figure 2 to be steeper over losses. If our positively framed aspirational message and images of happy families imply attainment of health gains $\triangle H$ in the figure, then an individual that begins at a "neutral" reference point $\mathrm{N}$ will evaluate such a message as having health gains $\triangle H$ and associated value represented by the vertical distance $V_{1}(\triangle H)$. However, for even a small but negative perceived "cost" of sickness $-\triangle S$ (for the sake of legitamacy we bound $-\triangle S$ below by $-\triangle H$ ), if first being reminded of the costs of sickness shifts a person's reference point from the "neutral" $N$ to "sick" $S$ in the figure, then the same positively framed message of the gains from POU usage will be evaluated as the vertical distance in the figure $V_{2}(\triangle H)$, with $V_{2}(\triangle H)>V_{1}(\triangle H)$. This

\footnotetext{
${ }^{12}$ Translations of the verbal scripts and accompanying images for both frames can be found in the Appendix. The positive or "contrast" frame visual images were shown to respondents via the use of marketing 'flip charts' carried by the survey enumerators. We gratefully acknowledge input on parts of the verbal script from members of the Rural Water Project (RWP) as well as Meyerowitz and Chaiken (1987) and Block and Keller (1995).
} 
is a direct result of people's tendency to overweight losses relative to gains. Simply put, by presenting the problem (contaminated water) alongside the solution (POU products), we anticipated loss aversion to cause people to be more likely to adopt POU products. Furthermore, a randomized test of social marketing performed in a nearby area of Kenya that included an aspirational message with emphasis on "good mothers treat their drinking water with WaterGuard" failed to induce a response (Kremer et al. 2009).

\section{Consistency with Public Commitment}

Another possible contributing factor to the low adoption rates of POU products is that people suffer from self-control problems and trade in future health benefits for the time savings of skipping POU treatment today. The standard neoclassical model assumes time-consistent preferences, but there is a wealth of evidence that people are impatient and weight the present period much more heavily than all future periods (DellaVigna 2009). Meanwhile, the "commitment consistency" psychological theory posits that people will go to great lengths to stay true to a commitment they have made in order to be, or appear to be, consistent (Greenwald, Carnot, Beach and Young 1987). This effect is strongest when that commitment is made in front of others (Cialdini 1993), possibly by incorporating social pressure into its effects. There is also evidence that predicting one's own future behavior can influence that behavior (Cialdini 1993).

However, the ability of this psychological tenet to affect real world behavior remains inconclusive and may depend on the context. Greenwald et al. (1987) find positive effects on voting behavior, but Smith, Gerber and Orlich (2003) fail to find a similar effect. Closer to our setting, Kremer and Miguel (2007) find no effect of asking adolescent respondents in Kenya to commit to taking a deworming drug on subsequent adoption. Webb and Sheeran (2006) perform a metaanalysis of 47 randomized trials in psychology that test the ability of this heuristic to influence a wide range of behaviors. They find small to medium effects on behavior due to randomized interventions that alter one's intentions and conclude that the intention-behavior link is present, but confounded by a variety of other factors that moderate this link.

Our study tests the ability of harnessing such "commitment effects" to induce greater POU product usage. At the end of each interview, as a new product was given to a household for a new two month trial, survey enumerators asked a randomly chosen half of participant households if they intended to use their assigned POU technology. ${ }^{13}$ Then, enumerators asked these respondents to promise aloud to use their safe water product to keep their family healthy. These respondents were then asked to predict if they would be found to be using their safe water product two months later

\footnotetext{
${ }^{13}$ The same half of respondents was given this treatment at each visit to reinforce earlier treatments.
} 
when the enumerator returned. At this point, these treatment households were given a photographic reminder of this commitment to hang in their homes. At the baseline visit, these photographic reminders were posters showing images of all three of the safe water products as well as images of happy, smiling mothers and children. ${ }^{14}$ After the first two month trial with a product, these same households were given a second, personalized poster that showed images of the products as well as a photo of the respondent herself that had been taken by the enumerator at the end of the baseline interview two months prior. ${ }^{15}$ The other "control" half of homes did not receive any additional messages or reminders of this sort.

Our priors were that this "commitment" treatment would induce greater product usage by making treated respondents self-identify as users and subsequently follow through with greater POU usage behavior. To explain our intuition, consider a multi-period model and let POU products be characterized as investment goods wherein the perceived "costs" of usage $c_{t}$ are incurred in the current period but the health benefits $b_{t+1}$ are not realized until the next period. Importantly, the treatment decision is made repeatedly in each period over an exponential time horizon. Formally, at time 0 , overall utility $U_{t}$ will be evaluated as $U_{t}=-\beta^{T} c_{0}+\sum_{t=1} \delta^{t}\left(b_{t}-c_{t}\right)$, where $\delta$ is the usual (time-consistent) discount factor, and $\beta^{T} \geq 1$ is a "present-biased" parameter that captures selfcontrol problems for certain agent types, with $T \epsilon\{P, I\}$ (O’Donoghue and Rabin 1999). "Patient" households have $\beta^{P}=1$ (the standard assumption), and do not weight the present period disproportionately at the expense of future periods. For homes with $\beta^{I}>1$, although ex ante they may intend to use their POU product, when the time comes to exert effort for its use in a given period, their "present-biased" preferences may cause them to delay. An agent will maximize the sum of costs from today (time 0) to infinity and benefits from tomorrow (time 1) to infinity. Suppressing the exponential discount factor $\delta$ for convenience, ${ }^{16}$ she calculates:

$$
-\beta^{T} c_{0}+\sum_{t=1}^{\infty}\left(b_{t}-c_{t}\right)
$$

\footnotetext{
${ }^{14}$ Figure A.3 in the Appendix shows the "commitment poster" delivered to treatment homes during the baseline visit. We thank Clair Null for this suggestion.

${ }^{15}$ Figure A.4 in the Appendix shows an example of a personalized "commitment poster" delivered to treatment homes at the first follow-up visit. These posters were intended to strengthen any effects from this commitment treatment by drawing on the "availability heuristic." Similar personalized posters were delivered to the "control" half of households at the final exit interview as these became valuable commodities in the community.

${ }^{16}$ For a day-to-day decision, any reasonable value for $\delta$ should be close to 1 . While mathematically we can derive the same predictions with a low discount factor $\delta$ over all periods instead of a present-biased parameter $\beta>1$ on the current period, for any empirically reasonable values of $\delta$ our results will hold. We take as evidence that households do not have such low $\delta$ the fact that they plant and harvest crops, behaviors that operate over a longer horizon than would be expected if these predictions were coming from a low discount rate instead of a present-biased parameter.
} 
If we assume for present-biased households with $\beta^{I}>1$ that $\beta^{I} c_{0}>b_{1}>c_{0}$, while a patient agent will treat her water $\left(b_{1}>c_{0}\right)$, an impatient agent will not $\left(b_{1}<\beta^{I} c_{0}\right)$. Note that in the current period, when planning for tomorrow, all agent types calculate:

$$
-c_{1}+\sum_{t=2}^{\infty}\left(b_{t}-c_{t}\right)>0
$$

Thus, although a naive procrastinator will not treat today, she looks at equation 2 and decides she will start treating her water tomorrow. The lifetime benefit is almost identical to 1 , but the cost is substantially lower when she starts tomorrow.

Our commitment treatment can be thought of as introducing shame if you break your word. Shame acts like a tax on waiting until tomorrow to start treatment, and reduces utility by $S$. We modify equation 1 as follows:

$$
-c_{0}+\frac{\sum_{t=1} \delta^{t}\left(b_{t}-c_{t}\right)}{\beta^{T}}>-S
$$

For patient households with $\beta^{P}=1$, a small amount of shame if they fail to treat lowers the daily "costs" of treatment. However, since they correctly solve 1 to begin with, they simply amortize this shame over an infinite horizon and the effects of noncompliance will be small (although we still predict a positive effect of commitment on treatment for these households). For impatient households, although ex ante they intend to solve 2, when the current period arises, they are short-sighted and instead solve $c_{0}>\frac{b_{1}}{\beta^{I}}>\left(c_{0}-S\right)$. That is, impatient households compare the immediate costs of treatment with the immediate psychological costs of noncompliance. Since our commitment treatment operates as a small tax on putting off treatment until tomorrow, impatient households are now more likely to begin treatment today under commitment.

In practice, we allow perceived costs and benefits of usage as well as $\delta$ and $\beta$ to vary across households $\left(c_{i 1}, b_{i 2}, \delta_{i}\right.$, and $\beta_{i}^{T}$ for household $\left.i\right)$ to allow for different usage decisions within treatment categories. As long as preferences are such that $\frac{b_{1}}{\beta^{T}}>\left(c_{0}-S\right)$ on average, this implies that treated homes whose preferences would put them at the margin of usage in the control condition are more likely to switch to using their POU products under treatment. This effect should be larger if ex ante people intend to adopt a POU product, but fall out of the behavior in a given period due to present-biased preferences $\left(\beta^{I}>1\right)$. 


\subsection{Information Interventions}

Another possible cause for low adoption rates of new technologies in developing countries is that individuals lack complete information. In the context of drinking water, being provided with information about household water quality can increase the likelihood of households adopting safe water behaviors. Madajewicz et al. (2007) find that informing rural Bangladeshi households about arsenic contamination levels in wells results in $60 \%$ of those with unsafe wells to switch, as compared to $14 \%$ of those with "safe" wells. Similarly, Jalan and Somanathan (2008) find that informing urban Indian households about the results of water quality tests results in an 11 percentage point increase in rates of adoption of safe water behaviors among households that had not been previously treating their water. However, Jalan and Somanathan (2008) rely on self-reported outcomes to measure the impact of information, which is likely upwardly biased: If households have been told their drinking water is contaminated, it may be socially difficult to respond that one is not doing anything to treat the water in response. Further, Jalan and Somanathan (2008) share information only on households' private stored supplies of drinking water. This design may not be cost effective as a policy approach and the authors do not consider the possibility that the provision of water quality information adds salience instead of expanding people's information set. Our study attempts to distinguish between these by sharing both common source, and personalized own, water quality information. Finally, their study did not provide free POU products in tandem with this information and they consider a relatively wealthy segment of an urban Indian population. ${ }^{17}$ This leaves the possibility that income effects will play a role in people's treatment decisions and ignores a huge segment of the developing world that is extremely poor and lacks access to safe drinking water. Closer to our setting, Kremer et al. (2009) argue that lack of awareness might not be a constraint to POU adoption in nearby Busia, Kenya, as a majority of households in their study understood the health benefits of using WaterGuard. However, in our baseline survey, we found that $42 \%$ of households (166 of 400) thought their drinking source was safe to drink without treatment despite $100 \%$ contamination rates among non-rain water catchment sources. Thus, it appears households may not possess complete information about water quality in Nyawita.

We test if lack of awareness about water quality is influencing POU adoption in our setting and if so, what type of information is necessary to increase POU adoption rates. We also test whether the effect of such information provision affects sustained behavior change in the medium-term.

To our knowledge this is the first formal test of how households respond to information about source water quality in comparison to information about own water quality and no information, respectively. The reasoning behind such a design is twofold. One, if information is a constraint to the

\footnotetext{
${ }^{17} 26 \%$ of their respondents own a computer.
} 
adoption of safe water behaviors, then the type of information necessary to bring about individuallevel behavior change matters. It is not feasible to ask local governments to test the quality of the drinking water in every household's private stored supplies, and moreover to do so repeatedly to keep such information up to date. If, however, the sharing of source water quality results can induce as great a response, then potentially a more practical policy prescription is born. Two, if the provision of information increases POU usage rates, it may be that the information inadvertently added salience to a known problem instead of uncovered an unknown problem. If this is the case, it suggests an avenue for well-designed marketing strategies instead of necessarily increasing educational messages. Our experiment tries to distinguish between these two hypotheses in order to draw better policy prescriptions.

Our ex ante hypothesis for this set of randomizations was that the information about own water quality would spur greater POU product usage than the source water quality results so long as both types of information show contamination, but that any information would induce greater POU usage than in the control condition. ${ }^{18}$ Formally, we outline our hypotheses as follows. Consider a simple model with two possible states of the world in any single time period: healthy and sick. Let consumers experience health $h=\alpha$ in the sick state and $h=\alpha+\theta$ in the healthy state. Thus, the "gain" to health in the healthy state is $\theta$ where $\theta>0$. Assume that prior to the baseline survey, consumers know their realized health in each state of the world from previous experience and hold priors on the probability of experiencing the healthy state, but due to incomplete information do not necessarily link the resulting states of the world in any period to their drinking water quality. Thus, prior to our baseline survey, assume in any period consumer $i$ has expected utility given by:

$$
E\left[U\left(h^{i}\right)\right]=\hat{p}_{0}^{i}(\alpha+\theta)+\left(1-\hat{p}_{0}^{i}\right) \alpha
$$

where $\hat{p}_{0}^{i}$ is consumer $i$ 's ex ante subjective belief about the probability of realizing the healthy state, and we assume $\hat{p}_{0}^{i} \sim F\left(p_{0}, \sigma_{p_{0}}^{2}\right)$. In this set up there is no decision for consumers to make to affect their realized utility in any period; they take whatever fortune they are dealt in each period. After the baseline survey and its associated educational component about the importance of clean drinking water and free POU product provision, consumers begin to relate their expected utility in any period to their decisions to use a POU product (i.e., this becomes an argument in their expected utility). Consumers form new beliefs $\hat{p}_{1}^{q i}$, with $\hat{p}_{1}^{q i} \sim F\left(p_{1}^{q}, \sigma_{p_{1}^{q}}^{2}\right)$, about the probability of realizing the healthy state in any period when using POU product $q$, where we assume $1 \geq p_{1}^{q} \geq p_{0}$. That is, on average consumers expect POU products to increase their chances of realizing the healthy state. Consumers will now use their POU product $q$ if the expected utility from doing so is greater

\footnotetext{
${ }^{18}$ We discuss responses to a "safe" personalized water quality test when we present results in section 4.
} 
than that from non-use. We can write:

$E\left[U\left(h \mid T^{q i}=1\right)\right]=\hat{p}_{1}^{q i}(\alpha+\theta)+\left(1-\hat{p}_{1}^{q i}\right)(\alpha)-C^{q} \geq E\left[U\left(h \mid T^{q i}=0\right)\right]=\hat{p}_{0}^{i}(\alpha+\theta)+\left(1-\hat{p}_{0}^{i}\right)(\alpha)$

where $T^{q i}$ is the treatment decision by consumer $i\left(T^{q i}=1\right.$ or $\left.T^{q i}=0\right)$, and $C^{q}$ are perceived "costs" of usage of product $q$ due to the time and effort involved. In expectation this decision simplifies to using POU product $q$ iff:

$$
\left(p_{1}^{q}-p_{0}\right) \theta \geq C^{q}
$$

The probability differential $p_{1}^{q}-p_{0}$ in (6) can represent consumers' average prior expectation about the gain from use of POU product $q$, and a consumer will use a POU product if the expected relative gain from doing so outweighs any costs in effort from use. ${ }^{19}$

When consumers are provided information about source water quality two months following the baseline survey, any uncertainty they may have had about the safety, or lack thereof, of available water sources is effectively eliminated. We model this as a downward shift in mean beliefs about the probability of realizing the healthy state in the absence of POU treatment $\left(p_{0}^{\text {source }}<p_{0}\right)$. This causes some households who did not satisfy 6 originally to now switch to usage of their POU product.

As explained in the introduction, we hypothesized that the provision of personalized water quality information might add salience to a household's decision and result in greater usage than the common source information if the two tests both show contamination. In our model we can think of this as further modifying consumers' expected utility over the sick state in the absence of POU usage. This salience effect can be thought of either as consumers further re-weighting the probability of the sick state in the absence of treatment disproportionately $\left(1-\hat{p}_{0}^{*} \geq 1-\hat{p}_{0}\right)$, or by decreasing their anticipated utility in the sick state from $\alpha$ to $\alpha+\gamma$ (with $\gamma<0$ ). If the provision of personalized water quality tests causes attention to focus on the bad outcome, instead of on the probability of its occurrence, this could increase its perceived "cost." Such a response has been hypothesized in other settings (Sunstein 2003). In either case, our ex ante prediction was that the personalized information would further increase POU product usage by adding "vividness effects." Empirically, we will make attempts to distinguish between our information treatments adding vividness effects and affecting people's perceived probabilities of sickness.

\footnotetext{
${ }^{19}$ Here we do not formally model the learning process consumers undergo to update beliefs on the quality of the POU products. Although expectations about product quality are sure to change following experience with them, this does not add to the intuition of the problem at hand.
} 


\section{Data Description and Summary Statistics}

\subsection{Data Collection Procedures and Measuring Product Usage}

At each household visit, enumerators performed a variety of tests to measure water quality and product usage. At the baseline visit, samples of water were drawn from a household's stored supply of drinking water and tested for fecal contamination via the presence of E. coli. (If a household reported their drinking water as chemically treated such as with WaterGuard or Pur, a chlorine test also was performed and results recorded.) At all subsequent visits including spot checks, households gave self-reports of usage, and chlorine tests were performed at homes assigned WaterGuard or Pur. At filter homes, enumerators recorded their own observations about usage. ${ }^{20}$ Because the included products treat at most $20 \mathrm{~L}$ of water at one time, and yet trips to collect drinking water often collect more than this amount, a common practice among respondent households was to have greater supplies of drinking water on hand than just treated drinking water. Ths enabled the collection of both untreated (pre-treated) and treated (post-treated) stored supplies of drinking water. All samples were tested for E. coli. ${ }^{21}$

As stated earlier, our measures of interest are usage of a POU product. We construct several different definitions of product usage, each with its own advantages and disadvantages. All presented results will be consistent across all usage definitions Where appropriate we will be careful to distinguish between POU product usage and other behaviors that our treatments potentialy could affect such as water collection. First, we rely on self-reports of product usage. Self-reports should be comparable across all three products yet likely overestimate actual usage due to courtesy bias. Another definition labels a household a "user" if its sample of treated drinking water met some threshold level of $E$. coli contamination. We consider levels of zero, and less than 10, coliform forming units (CFU) of E. coli per $100 \mathrm{~mL}$ of water. ${ }^{22}$ Zero E. coli is the WHO internationally recommended level for no risk of contracting illness from drinking water, and E. coli contamination levels <10 CFU/100 mL qualify as "low risk" according to WHO guidelines (WHO 1997). However, such definitions fail to take into account the quality of the corresponding pre-treated drinking

\footnotetext{
${ }^{20} \mathrm{To}$ avoid discussion of product-specific effects of our marketing and information treatments, we do not present results for these product-specific definitions of usage. A positive chlorine test is likely a lower bound on actual usage of WaterGuard and Pur due to the dissipation of chlorine over time, and is not comparable to enumerator observations of filter usage. All results presented are consistent with these definitions of product use.

${ }^{21}$ Fewer samples were collected when pre-treated or post-treated supplies were unavailable. More details on the water testing procedures can be found in the Appendix.

${ }^{22}$ For convenience, throughout the paper we call an E. coli measurement of $<1 \mathrm{CFU} / 100 \mathrm{~mL}$ to be zero. Our tests for $E$. coli are not able to detect $E$. coli contamination levels below $<1 \mathrm{CFU} / 100 \mathrm{~mL}$, but this satisfies WHO drinking water quality guidelines.
} 
water, and they arguably incorporate product efficacy into their definitions, which is independent of a household's behavior. Despite these potential drawbacks, these definitions present several advantages: We can compare these measures to "counterfactual" measures of usage by considering the contamination levels of corresponding untreated (pre-treated) samples to check if it is POU treatment that is the behavior affected by our randomizations; also, all of the persuasion and information randomizations were implemented orthogonally to product assignments, and therefore product efficacy should not affect these results. Additionally, we will include product fixed effects in some estimations to control for differences in product performance and base rates of product usage. A final definition of "usage" is an indicator for whether a household's treated water tested negative for contamination and pre-treated water tested positive for contamination. This is a clear indication of (competent) usage, but excludes those homes for which we lack both pre-treated and post-treated samples and furthermore classifies "incompetent" users as nonusers.

In addition to these dichotomous measures of product "usage," we construct a continuous measure: the natural log of the actual count (Most Probable Number, or MPN) of E. coli CFU/100 mL in a household's "drinking water" (we define "drinking water" to be a household's treated water if present or, if only untreated water is on hand at the time of the interview, we label it as the household's drinking water). ${ }^{23}$ For this continuous measure, smaller (more negative) values imply greater usage.

\subsection{Data Description and Tests of Randomizations}

Our study included many different types of randomizations, all implemented orthogonal to each other, with the exception of the village-level information randomizations. We did not anticipate and therefore do not test for interactive effects across the independently assigned randomizations, but in Table A.1 in the Appendix we do present cell sizes for each combination of randomizations within each post-baseline wave. Average post-baseline cell size is 10.5 households that receive the same product (WaterGuard, filter or Pur), frame (positive or contrast), commitment treatment assignment (treat or control), and initial information treatment (zero, source, or source + own) in a given wave. Six cells have the minimum cell size of seven households and fifteen cells have the maximum cell size of 13 households. Baseline cell sizes are larger due to there being no information or product assignments at this point in the study.

We do not present comparisons of equality across treatment categories in baseline descriptive statistics for each treatment individually due to the many points of randomization. Rather, we summarize by saying that for 55 baseline household descriptive variables compared across each

\footnotetext{
${ }^{23}$ For cases with zero $E$. coli counts, we substitute -1 for their log values in order not to drop these observations.
} 
individual-level randomization assignment of first product assigned, framing message received, and commitment treatment received, nearly all balance. Specifically, 54 of the $55(98 \%)$ baseline descriptive variables are balanced ( $p$-value $>.1$ for F-test of equality of means) across first product assigned; 52 of 55 (92\%) balance (p-value $>.1$ on t-test for equality of means) across frames; and 53 of $55(96 \%)$ balance (p-value $>.1$ on t-test for equality of means) across commitment treatment status. Furthermore, all baseline variables describing a household's water quality and collection habits balance across the individual-level randomizations. We therefore feel confident that our individual-level randomizations worked.

The village-level information randomizations had more pre-treatment differences. In general, wealthier, more educated villages were assigned to receive the information treatments first. However, this treatment was implemented during the two-month follow-up survey round, after all households had been provided a free POU product for two months; at this follow-up survey round, all variables describing household water quality and product usage are balanced (p-value > .1) across information treatment groups. Arguably any upwards bias that may result from staggering wealthier villages into the information treatment first are attenuated by the timing of this treatment. Furthermore, it is possible that such an imbalance across treatment groups will bias any estimated effects of information downwards if the information treatments operate primarily via the channel of expanding people's information sets and the wealthier, more educated villages had greater baseline awareness. Finally, given that all homes were provided with free POU products, any bias on behavior due to income effects will be mitigated. ${ }^{24}$

Table 1 presents baseline summary statistics of households included in the study. Most (53\%) homes rely on farming as their main income source, and just $18 \%$ of respondents report an education level beyond primary. Average household size is about 6 people, and $89 \%$ of respondents are female. ${ }^{25}$

Average water quality at baseline is poor. $86.5 \%$ of household stored water samples taken during the baseline survey tested positive for $E$. coli and therefore posed a nonzero risk of contracting waterborne illness. According to WHO guidelines on the relative risk posed by different levels of E. coli coliform forming units for waterborne illness, the median household had baseline drinking water contamination levels that put them at intermediate risk for contracting illness.

Baseline knowledge of the causes of diarrhea include a constructed "diarrhea knowledge index" (DKI) that counts the number of valid responses to the question of methods for the prevention of diarrhea. This question was asked without the enumerator offering potential responses, and

\footnotetext{
${ }^{24}$ Results of all baseline comparisons are available upon request.

${ }^{25}$ In $11 \%$ of households, a male respondent was interviewed if no adult female was available.
} 
households were prompted three times to name as many prevention methods as they could. ${ }^{26}$ The average respondent was able to name between 4-5 means of diarrhea prevention, which suggests moderate awareness and more than than that found in nearby Busia, Kenya by Kremer et al. (2007). Despite this, $89 \%$ of baseline respondents strongly agreed with the statement, "Diarrhea is a natural occurence in childhood." 27

Over the total 8 months duration of the study, 30 of the original 400 households dropped out, resulting in an overall retention rate of $92.5 \%$. Between each successive full round of surveys, retention rates were $97 \%, 98 \%$ and $98 \%$, respectively. ${ }^{28}$ By far the most common reason for a household to drop out of the study was migration to an urban area. As such, homes that attrited were generally younger families, and were slightly better educated and wealthier. Attrited homes were also more likely to have previous POU experience: $63 \%(38 \%)$ and 67\% (43\%) of attrited (non-attrited) homes reported previous purchases and use of WaterGuard, respectively ( $\mathrm{p}$-value of .0073 (.0131) on two-sided t-test of equality). These differences suggest that our estimates of usage are most representative of a persistently rural population and may not apply to more urban and mobile households. Attrition does not appear related to a household's assigned product or other randomized treatment assignments (Chi-squared test p-value is .16 on a probit regression that predicts drop out as a function of all treatment assignments; estimation not shown).

\section{Estimation Strategy and Results}

We identify the effects of our various persuasion tactics and the different types of water quality information on product usage using the randomly and independently assigned variation of each of these elements of the study design.

\subsection{Base Impacts of POU Product Provision}

Mean rates of POU product usage vary by the definition of product "use," but all measures show vast improvements over baseline measures of water quality and a consistent pattern across survey waves, products, and our various marketing and information interventions. Table 2 summarizes

\footnotetext{
${ }^{26}$ This question is borrowed from Kremer, Leino, Miguel and Zwane (2007) and we gratefully acknowledge their input. Potential valid responses include "boil drinking water," "drink only clean water," "use latrine," "proper cooking of food," "don't eat spoiled food," "eat clean/protected/washed food," "wash hands," "solar water disinfection," "good hygiene practices," "medication," “clean dishes/utensils," "breastfeeding," "use compost pit/keep compound clean."

${ }^{27}$ This compares to a rate of $70 \%$ of those surveyed in rural Bolivia that agreed with this in Quick, Mintz, Sobel, Mead, Reiff and Tauxe (1997) (as cited by Jalan et al. 2008).

${ }^{28}$ Figure 1 contains actual household counts for each round.
} 
usage results across user definitions and products. As expected, self-reported user definitions result in the highest rates of usage: $72 \%$ of households self-report current use of their assigned POU product two months after receiving it across all survey waves and all products. These usage rates vary by POU product, with $77 \%$ of WaterGuard homes self-reporting usage compared to $75 \%$ of filter homes and $62 \%$ of homes with Pur on hand (p-value of 0.000 on three-way F-test for equality of means). Such usage rates are high in comparison to a baseline self-reported usage rate of $7 \% .^{29}$

Although self-reported usage measures may be inflated upwards on an absolute scale due to courtesy bias, the pattern they reveal of higher usage for WaterGuard and the filter relative to Pur is consistent with objective measures of product use. Table 2 shows that relative usage patterns for the three POU products remain consistent across definitions. and that all products are effectively cleaning the households' drinking water. ${ }^{30}$ Across all follow-up survey rounds and products, $41 \%$ of households were found to have drinking water with zero measurable E. coli in their stored, treated drinking water, and $57 \%$ of households had treated drinking water that qualifies as "low risk" for causing illness according to WHO guidelines (with an E. coli MPN < $10 \mathrm{CFU} / 100 \mathrm{~mL}$ ). These rates can be compared to baseline rates of $13.5 \%$ and $38 \%$, respectively. ${ }^{31}$

Comparing usage rates between baseline and all follow-up rounds ignores the clear seasonal trends affecting untreated water quality at each survey wave as well as the cumulative effects of time and experience. As a household gains experience with a product, it is possible that it may develop a "taste" for safe drinking water and POU treatment becomes habitual. This would be encouraging news for the long term sustainability of POU measures. If instead households grow tired of POU water treatment with experience, it suggests that sustained behavior change is one impediment to the long term potential of POU treatment measures to expand access to safe drinking water.

Figure 3 graphs water quality trends over the length of exposure with a product by counting the total number of days a household has had a product. Because of the small size of our enumerator team relative to the sample size, each set of household visits was staggered over several weeks. This, combined with the spot-check visits made to a subset of households during each product

\footnotetext{
${ }^{29}$ Definitions of self-reported usage are not exactly identical between baseline and all subsequent rounds due changes in survey design. It is hard to imagine this has much effect on the dramatic increase in usage rates postbaseline.

${ }^{30}$ In a companion paper, we discuss relative cleaning performance of the three products in more detail. We do not such results here in order to focus on the effects of our information and marketing interventions on overall usage.

${ }^{31}$ They can also be compared to rates of $E$. coli contamination of untreated water samples at each survey round to better account for seasonal changes in source water quality. In such a comparison, across the three follow-up survey rounds, $12 \%$ and $31 \%$ of households' untreated water samples had E. coli measurements of zero or less than 10 CFU/100 mL, respectively, reflecting in part the general deterioration in available water quality from baseline as the seasons changed from rainy to dry over the course of the study.
} 
rotation, enables us to examine the relationship between time exposure to products and product usage. Figure 3 draws nonparametric plots for the share of homes with no detectable E. coli in both untreated and treated water and combines into one continuous measure of exposure the intermediate spot checks (for which we have fewer observations) and full follow-up survey rounds. A stark definition of product usage can be thought of as the vertical distance between the untreated and treated lines. This figure combines all survey waves and all products, so seasonality and product performance do not affect these results. Figure 3 shows that initial uptake of the POU products is very high, but drops off relatively quickly. However, by the two-month follow-up surveys, rates of product usage appear more or less steady. Such a usage pattern suggests most households initially adopt, but with experience some households learn they do not like the products or tire of the behavior of water treatment. Others appear to develop a habit of water treatment and this remains over time. We next look at how our marketing and information interventions affect these overall usage patterns.

\subsection{Impact of Persuasion and Information Interventions}

We first consider the persuasion randomizations independently to test whether each affects product usage. Later we will introduce multivariate regression techniques to control for confounding factors, but the nonparametric identification of effects is cleanest with the basic comparison of means (Freedman 2008). We therefore begin by combining all post-treatment waves of data (i.e., all waves after the baseline that are subject to being affected by our randomized treatments) and estimate the impact of treatment using univariate linear regression ${ }^{32}$ :

$$
Y_{i p t}=\alpha+\beta_{M} T_{i}^{M}+\varepsilon_{i t}
$$

where $Y_{i p t}$ is a measure of usage of product $p$ at time $t$ by household $i$, and $T_{i}^{M}$ is an indicator for either the framing treatment ( $T^{F}=1$ for "contrast" frame, 0 otherwise) or commitment treatment ( $T^{C}=1$ if assigned, 0 otherwise). Due to the randomized assignment to treatment for both manipulations, $\beta_{M}$ should deliver unbiased estimates of their effects on product usage. We cluster the error terms $\varepsilon_{i t}$ at the household to allow for correlated outcomes across survey waves for the same household.

\footnotetext{
${ }^{32}$ Results are consistent if we estimate marginal probit effects for all 0/1 usage definitions. For ease of interpretation, we present results from linear probability regressions for all $0 / 1$ usage outcomes.
} 


\section{Framing}

Panel A of Table 3 contains results for the effects of our framing treatment on POU adoption. Across the various definitions of product use, we find consistent and reasonably strong evidence that the "contrast frame" is more effective than a "positive only" frame at inducing product use. Although not always statistically significant, the magnitude and direction of the estimated effect sizes all suggest the superiority of contrasting what one stands to lose from not committing a behavior with what one stands to gain from adoption of the behavior over focusing solely on the potential gains. Moreover, the effect sizes are illuminative: Column 1 in panel A of Table 3 shows that contrast frame homes are nearly 6 percentage points more likely to have "safe" treated water at home (p-value of 0.06 ), representing a nearly $15 \%$ increase in usage over that of the "positive only" households. Column 5 of panel A table shows that contrast frame households had an average $E$. coli count in their "drinking water" that was .43 log points lower than that found in positive frame households, which translates into $36 \%$ lower contamination levels.

We argue that the contrast frame is realizing an effect via product usage (i.e., treatment), and did not differentially affect other behaviors related to water collection or storage. Column 3 of Table 3 shows that among those households where both pre-treated and treated water samples were collected, households that received the contrast frame are nearly 8 percentage points more likely to have treated water with no contamination despite contaminated pre-treated water (p-value of .04). Column 4 of Table 3 shows that the share of respondents that self report treatment is 5 percentage points greater among the contrast frame households (p-value of .07). Since it is not clear that the two framed messages would differentially affect any courtesy bias inflating these numbers, such differences are notable. Finally, we compare column 1 (2) with column 6 (7). While column 1 (2) shows that the contrast frame increased rates of treated water with zero ( $<10 \mathrm{CFU} / 100 \mathrm{~mL}) E$. coli, there is no difference across frames in the corresponding rates of untreated water meeting this same quality threshold.

Figure 4 graphs separate nonparametric plots of usage trends over the length of exposure with a product by framing treatment and shows that the effect of the contrast frame remains constant, despite the general trend of decreasing POU usage over time that we also saw in Figure 3. Figure 4 combines all spot checks and full survey rounds into one continuous measure of the number of days' exposure to a product, and combines all survey waves and all products, so seasonality and product performance do not affect these results. ${ }^{33}$ Because the effect of the framing treatment does not appear to dissipate over time, we argue that the contrast frame operated as we hypothesized in

\footnotetext{
${ }^{33} \mathrm{We}$ do not graph corresponding confidence intervals since these differences are statistically significant only at their means (p-value .06) and not along their entire distributions, due to the design of our initial power calculations.
} 
Figure 2 via shifting respondents' reference points. If the framing treatment operated via playing on respondent emotions, we would expect the effect of the framing treatment to disappear over time.

Although Figure 4's results are only suggestive, the finding that a simple marketing appeal that merely frames the POU usage decision in a new light may be able to affect behavior up to 11 weeks after it is given (the maximum time in Figure 4) suggests that marketing could be one under-realized avenue for increasing POU adoption rates. Since our framing treatment could be effectively free to scale up, it could be one worthy of further investigation.

\section{Commitment}

Results from estimation of equation 7 for the commitment manipulation are listed in panel B of Table 3. Across the various definitions of product use, the commitment treatment consistently results in higher rates of usage, although these differences are not uniformly statistically significant. Column 1 shows that the commitment treatment is estimated to increase the likelihood of a household having zero $E$. coli contamination by around 6 percentage points, or a nearly $15 \%$ rise in usage over control homes (p-value .06). Columns 2, 3 and 4 show that the estimated effect size from this treatment is not sensitive to the precise definition of usage: All estimate that committing oneself to using a POU product increases rates of POU usage on the order of 5-8 percentage points. Although we believe the estimated treatment effect will be inflated by courtesy bias for rates of self-reported usage, results with this definition do not differ substantially from others (column 4). Column 5 of panel B in Table 3 suggests that commitment-treated homes have slightly better drinking water quality, although this difference is not statistically significant.

Again, this marketing manipulation appears to have realized an effect via product usage and not through some other behavioral channel such as water collection habits. If we compare treated and untreated water samples across commitment treatment status by looking at columns 1 and 6 ( 2 and 7) in tandem, we see that the commitment treatment increased rates of treated water having no detectable ( $<10 \mathrm{CFU} / 100 \mathrm{~mL})$ E. coli by $6(5)$ percentage points (p-value $.06(.17)$ ), but had no effect on the rates of untreated water that met this threshold (p-value .87 (.16)).

These average treatment effect (ATE) estimates of the commitment manipulation may hide heterogeneous effects if indeed it served as a commitment device for those respondents with presentbiased preferences. Since all respondents assigned the commitment treatment received it (i.e., there was no effective take-up decision for respondents since none refused to verbally commit to using their POU product ${ }^{34}$ ), its effects should be lower among those treated homes that are not present-

\footnotetext{
${ }^{34}$ In addition, $99 \%$ of respondents predicted they would be found to be using their POU product in two months'
} 
biased ( $\beta=1$ in equation 3 ) or are already sophisticated about their present-biased preferences and take actions to address them. Our baseline survey tried to identify respondents with present-biased preferences by asking a hypothetical question if they prefer to receive 50 Kenyan shillings (Ksh) today or $100 \mathrm{Ksh}$ in one week. Although the credibility of such hypothetical questions is subject to question (see discussion of alternative interpretations of such questions in Ashraf, Karlan and Yin (2006)), it provides a crude approximation of those homes we expect to benefit most from a commitment device. 127 of 400 (32\%) baseline respondents preferred $50 \mathrm{Ksh}$ today, and these respondents are evenly distributed across the randomized commitment treatment (p-value of .24 on two-sided t-test of equality). We label those households that prefer 50 Ksh today "present biased" (with an implied weekly discount rate of greater than 100\%), while the other households we label "patient." Being "present biased" does not appear related to a household's observable wealth or other characteristics. Across the same 55 baseline descriptive variables for which we tested the different randomizations in section 3 (excluding the indicator for being present-biased), we find that 51 of $54(94 \%)$ are balanced (p-value of $>.1$ on two-sided t-test) across this categorization, including the rates of households that have soap in the home, report a chlid having diarrhea in the previous two weeks, own a radio, own an iron roof, report liquidity constraints, and have a latrine. We therefore believe our definition of present-biased households is identifying its intended subgroup and we calculate the effects of the commitment treatment among patient and present-based households separately.

Table 4 contains results. The average commitment treatment effect is much larger among present-biased households: Committing oneself to use a POU product leads to a 12 percentage point rise in rates of households with no detectable $E$. coli in their treated water two months later, a 35\% increase (column 2). Among the "patient" households that opted for $100 \mathrm{Ksh}$ in one week, the estimated effect size is much smaller and insignificant (column 1). This same effect is seen when usage is defined as a continuous measure as the log of "drinking water" quality (columns 3 and 4). These results suggest that the commitment treatment operated as we hypothesized, and affected those homes that needed it most: those with "present-biased" preferences that are most likely to drop out of POU usage in any given period.

\section{Information Sharing + All Effects Combined}

As the information treatments were introduced in a staggered fashion over time and randomized at the level of villages, we modify equation 7 to estimate their effects while controlling for confounding seasonality and other effects. Equation 8 presents an intention-to-treat (ITT) estimator of

time when the enumerator returned. 
all of our randomizations including the effect of the two types of water quality information shared (source and own results):

$$
Y_{i p t v}=\alpha_{t}+\alpha_{p}+\beta S_{v, t-1}+\delta O_{v, t-1}+\theta F_{i t-1}+\lambda C_{i t-1}+\varepsilon_{i p t v}
$$

$Y_{i p t v}$ is a measure of usage of product $p$ by household $i$ at time $t$ in village $v . S_{v, t-1}$ is an indicator variable that takes on a value of 1 if households in village $v$ received information about source water quality at a previous visit to induce a response at timet. $O_{v, t-1}$ is another indicator variable that equals 1 if households in village $v$ received information about their own private stored supplies in addition to source water quality results, $S_{v, t-1}$. Thus, in practice $O_{v, t-1}$ tests if the sharing of personalized water quality results affects POU usage above and beyond that realized by the sharing of common source water results. To separate out the effects of our other marketing treatments we include $F_{i t-1}$ as an indicator of household $i$ receiving the contrast framing treatment in a previous wave, and $C_{i t-1}$ indicates household $i$ received the commitment treatment in a previous wave. We include survey wave fixed effects $\alpha_{t}$ to control for any common time-varying factors such as seasonality, and we include product fixed effects $\alpha_{p}$ to control for differential base rates of usage or cleaning performance across products. We cluster disturbance terms $\varepsilon_{i p t v}$ at the village to allow for correlated outcomes within villages due to the village-level assignment of the information treatments. The independent and randomized assignments to all treatments imply that each $\beta, \delta$, $\theta$, and $\lambda$ coefficient in equation 8 is an unbiased estimate of the reduced form ATE effect of that particular treatment on usage. As we had no strong priors about there being any interactive effects between these various randomized treatments, we do not test for them here.

We will also estimate "treatment on the treated" (TOT) effects of our randomized treatments. Specifically, we will estimate separate effects of the personalized information for those households that receive a "safe" versus "contamined" result by interacting the $O_{v, t-1}$ dummy from equation 8 with an indicator for whether a household received a "contaminated" personal water test result, as well as separate effects of the commitment treatment for patient and present-biased households by interacting the dummy $C_{i, t-1}$ with an indicator for a present-biased household. We anticipate the effects of a "contaminated" personal test result to be more vivid, and hence induce greater POU usage (and therefore we consider this the "treatment on the treated" (TOT) estimation of this treatment), than a "safe" result. However, it is likely that personal water quality is endogenous to household behavior. We therefore interpret these results with caution.

Table 5 contains the results of estimation of equation 8 . Note that equation 8 does not impose linearity since all explanatory variables are dummies, and thus the coefficients are estimates of the 
differences in conditional means of $Y_{i p t v}$. Table 5 suggests that the sharing of source water quality information significantly increases POU product usage and that the sharing of own water quality information does not encourage further usage. Column 1 shows that the percentage of households with zero $E$. coli in their treated water increased by nearly 10 percentage points (significant at the $5 \%$ level), or about a $22 \%$ increase over the mean base value across the three POU products, ${ }^{35}$ in response to the provision of source water quality information. The additional sharing of own water quality results does not further increase usage. Column 2 presents TOT effects of the personalized information and the commitment treatment. It suggests that the sharing of a "contaminated" personalized water test result does not spur greater usage and may even have deterrent effects, although the standard errors are too large to draw inference. It also suggests that our commitment treatment affected the present-biased subsample of households most strongly, in accordance with findings from Table 4. Columns 3 and 4 present ATE results with alternate indicators of usage, and both continue to suggest that the provision of source water quality information positively affects usage. Column 5 shows that the sharing of source water quality results leads to a statistically significant $.6 \log$ reduction in a household's drinking water $E$. coli, which translates into approximately a $49 \%$ reduction in contamination levels.

Figure 5 presents the average rates of usage (defined as having treated water E. coli MPN $<10$ $\mathrm{CFU} / 100 \mathrm{~mL}$ ) across the three information groups. In the figure, the dashed red and blue lines together constitute the effects of sharing "source" results, while the red lines alone constitute the sharing of own water quality results. Solid black lines represent having received no water quality information. The vertical lines in this figure mark the introduction of groups into a new information treatment category. To overcome the strong seasonality affecting all results, time effects have been de-meaned by comparing across the three information treatment groups within each wave. Thus, within a wave, the sum total of relative usage rates across the three groups will be zero. This means that the convergence seen in Figure 5 at the final survey wave to zero implies that the additional provision of personalized water quality information to two-thirds of villages does not result in higher usage than in those villages that receive only common source information. The "late treatment" group of villages is able to "catch up" to the villages that received information earlier. Furthermore, the additional provision of personalized water quality information does not result in any higher usage for these villages. Any differences in mean usage rates for the three groups on the left side of this figure at the two month survey wave (which is time zero for the information treatments) reflect shortcomings of the village-level randomization.

\footnotetext{
${ }^{35}$ Mean "base" values cited in table 5 are from the first two-month follow-up survey. We exclude all pre-treatment (baseline) data from this estimation since all treatments affect behavior only at points in time after the baseline interview. Results are not sensitive to the exclusion of baseline data nor the choice of "base" usage values.
} 
Column 6 of Table 5 presents results of equation 8 where the dependent variable is an indicator that equals 1 if a household's untreated water had an E. coli MPN $<10$ CFU/ $100 \mathrm{~mL}$. Although only statistically significant at the $10 \%$ level, the magnitude of the estimated effect suggests that a portion of the source information "treatment" is to encourage better selection of water sources, i.e., those that are less contaminated. This same definition of usage when applied to a household's treated water shows a statistically significant rise in usage of 13 percentage points (column 3), which implies that about half of the source information treatment is being exercised through improved collection practices (ignoring differences in levels of statistical significance). ${ }^{36}$ Yet the script that households received for the source water information treatment only specified that all of the source water in Nyawita had tested positive for contamination; it did not present results of relative levels of contamination across sources. ${ }^{37}$ Thus, it was up to respondents themselves to infer which were the relatively cleaner sources. They were seemingly able to do so. A related estimation suggests that households spend an average of about 6 additional minutes collecting water in response to learning source water results (results not shown). Furthermore, at each wave our survey asked whether respondents believed their drinking water to be "safe" without treatment when collected from their chosen source. At baseline, $42 \%$ of homes thought their source was "safe" without treatment. At the first follow-up survey two months later, just 7\% of homes thought their drinking water was "safe." Although this latter statistic is surely inflated upwards due to courtesy bias as homes had just enjoyed two months with free POU products, because of the timing of this treatment, it means that $93 \%$ of homes self-reported their source water to be unsafe before any households were provided the results of source water quality tests. The fact that the source water quality information nevertheless had such a large effect on behavior suggests that for many it may have added salience to a known problem versus uncovering an unknown one. It is possible the script still appealed to an "availability heuristic" since the common source results were from respondents' local area. It is also possible it appealed to respondent emotions, since the script specified that the source waters in Nyawita had tested positive for the presence of human feces in the water, i.e., it did not use terms like "contamination" or "germs" that might have no meaning to respondents with low education levels.

From a policy perspective, it can be construed as good news that the sharing of village-level water quality tests can realize all the benefits of personalized information (in tandem with free POU

\footnotetext{
${ }^{36}$ Since our study distributed improved storage containers with all products at all waves, differential storage behaviors would not seem to bring about this effect.

${ }^{37}$ The source water quality script did make the allowance that rain water may be free from contamination when collected. However, it emphasized that a good way to be certain one's water was safe was to use a POU product such as the one provided by our study.
} 
products). However, it also suggests caution when evaluating the importance of a one-time information provision as a policy tool to increase adoption of these technologies. It is unclear whether any policy prescription that relies partly on salience effects can achieve lasting behavior change. The tendency of households to "drop out" of the habit of water treatment over time (Figures 3 and 4 ), suggests that it may take repeated marketing or psychological "treatments" to maintain health behaviors.

\section{Conclusions}

The decision to adopt a technology only begins with the decision about whether or not to purchase it. Subsequent to its purchase, it must be used in order to deliver any benefits. When a technology like a POU product necessitates such a decision to be made on a repetitive basis, behavior change often becomes a binding constraint to its successful long term adoption. Our experiment considered the roles of information and marketing in achieving behavior change in the use of free POU safe water technologies. We find that providing households information about source water quality can increase POU usage rates by 8-13 percentage points, and that the sharing of personalized water quality results does not further increase use. We also find that marketing messages that incorporate psychological heuristics can increase adoption rates on the order of 3-8 percentage points overall. In particular, contrasting what one stands to lose from non-adoption with what one stands to gain from POU adoption induces greater product usage than that achieved by focusing solely on the potential gains. This result contradicts current conventional wisdom among social marketers of these products, who argue for positively framed messages that ignore any mention of disease. Pointing out the costs of non-adoption in marketing materials potentially could be a simple and affordable way to increase POU adoption by a small but measurable amount. Finally, we find that among the $32 \%$ of households we label "present-biased" due to their response to a hypothetical question on time preference, our commitment treatment realizes a large effect on behavior; commitment-treated present-biased households were 12 percentage points more likely to have no detectable $E$. coli in their treated water two months later.

These results are of a similar magnitude to the "short run" ( 3 week) results found by Kremer et al. (2009) for their persuasion treatments to encourage use of WaterGuard in nearby Busia, Kenya, but larger than their "medium-run" results that found no effect of their persuasive appeals on usage. Their study's medium-run effects were estimated 3-6 months following treatment while the maximum amount of time elapsed to estimate our study's effects of the information and marketing campaigns was about 2.5 months, and it is impossible to say if this is one cause for the different 
findings. Other possible explanations include that our marketing messages appealed to different psychological heuristics, the two studies were in different areas with different source water quality, and we had three different POU products, all provided for free. Our findings are also on par with those of Ashraf et al. (2007) for their estimates of the causal effect of pricing on usage of a chlorine product in urban Lusaka, Zambia.

In sum, our results can help to shed light on some of the informational and behavioral constraints to POU adoption as well as promising avenues for incremental improvements in the use of POU technologies. However, despite free product provision and a variety of marketing and information tactics undertaken, we never approach $100 \%$ use of these private health products. A common policy objective is universal access to safe drinking water. Our findings suggest that relying on the behavior of private individuals to achieve this goal may be unwise.

Like most field experimental results, the external validity of our findings is subject to question. Towards this end, we are in the process of replicating our study in the urban slums of Dhaka, Bangladesh. Primary water sources in Dhaka's slums are municipal taps, and levels of contamination are very high among participant households. In our Dhaka study, we have a different mix of POU products but similar marketing and informational tests. If our findings from urban Bangladesh are found to confirm those from rural Kenya presented here, we will gain greater confidence in the external validity of our results. Furthermore, by harnessing well known psychological heuristics in a predictable way in two very different settings using different technologies, our two studies could help to uncover new insights into people's decision-making processes more generally. Such findings could contribute to the growing behavioral economics literature that seeks to improve upon the standard model of behavior and thereby help develop new strategies to encourage the adoption of a variety of behaviors or technologies.

\section{References}

Adetunji, J. and D. Meekers, "Consistency in Condom Use in the Context of HIV/AIDS in Zimbabwe," Journal of Biosocial Science, 2001, 33, 121-138.

Agarwal, Sumit and Brent W. Ambrose, "Does it Pay to Read Your Junk Mail? Evidence of the Effect of Advertising on Home Equity Credit Choices," FRB of Chicago Working Paper No. 2009-09, 2008, November 21.

Ashraf, Nava, Dean Karlan, and Wesley Yin, "Tying Odysseus to the Mast: Evidence forma Commitment Savings Product in the Philippines," The Quarterly Journal of Economics, May 2006, 121 (2), 635-672. 
_, James Berry, and Jesse Shapiro, "Can Higher Prices Stimulate Product Use? Evidence from a Field Experiment in Zambia," NBER Working paper No. W13247, July 2007.

Bertrand, Marianne, Dean Karlan, Sendhil Mullainathan, Erik Shafir, and Jonathan

Zinman, "What's Advertising Content Worth? Evidence from a Consumer Credit Marketing Field Experiment (January 23, 2009)," Yale University Economic Growth Center Discussion Paper No. 968; Yale Economics Department Working Paper No. 58, 2009.

Black, Robert E., Kenneth H. Brown, and Stan Becker, "Effects of Diarrhea Associated with Specific Enteropathogens on the Growth of Children in Rural Bangladesh," Pediatrics, June 1984, 73 (6), 799-805.

Block, L.G. and P.A. Keller, "When to Accentuate the Negative: The Effects of Perceived Efficacy and Message Framing on Intentions to Perform a Health-Related Behavior,' Journal of Marketing Research, 1995, 32 (May), 192-203.

Brown, J. and M. Sobsey, "Independent Appraisal of Ceramic Water Filtration Interventions in Cambodia: Final Report," Report submitted to UNICEF, 2006.

CDC, “Safe Water System: A Low-Cost Technology for Clean Drinking Water," Technical Report, CDC: Centers for Disease Control and Prevention, Atlanta, GA 2006.

Chiller, T., C. Mendoz, M. Lopez, M. Alvarez, R. Hoekstra, B. Keswick, and S. Luby, "Reducing Diarrhoea in Guatemalan Children: Randomized Controlled Trial of FlocculantDisinfectant for Drinking-Water," Bulletin of the World Health Organization, 2006, 1.

Cialdini, R.B., Influence: The Psychology of Persuasion, New York: Morrow, 1993.

Clasen, T., G. Garcia Parra, S. Boisson, and S. Collin, "Household-based Ceramic Water Filters for the Prevention of Diarrhea: A Randomized, Controlled Trial of a Pilot Program in Colombia," American Journal of Tropical Medicine and Hygiene, 2005, 3 (4), 790-795.

, I. Roberts, T. Rabie, W. Schmidt, and S. Cairncross, "Interventions to Improve Water Quality for Preventing Diarrhoea (Review)," The Cochrane Library, 2006, 4.

Crump, J.A., P.O. Otieno, L. Slutsker, B.H. Keswick, D.H. Rosen, R.M. Hoekstra, J.M. Vulule, and S.P. Luby, "Household Based Treatment of Drinking Water with Flocculant-Disinfectant for Preventing Diarrhea in Areas with Turbid Source Water in Rural Western Kenya: Cluster Randomized Controlled Trial,” British Medical Journal, 2004, 331 (7515), 478-484.

DellaVigna, Stefano, "Psychology and Economics: Evidence from the Field," Journal of Economic Literature, 2009, 47, 315-372.

Duflo, Esther, Michael Kremer, and Jonathan Robinson, "Why don't farmers use fertilizer: Evidence from Field Experiments in Western Kenya," working paper, 2007. 
Foster, Andrew and Mark Rosenzweig, "Learning by Doing and Learning from Others: Human Capital and Technical Change in Agriculture," The Journal of Political Economy, 1995, 103(6), 1176-1209.

Freedman, David A., "On regression adjustments to experimental data," Advances in Applied Mathematics, 2008, 40 (2), 180-193.

Gass, R.H. and J. Seiter, Persuasion, Social Influence, and Compliance Gaining, third ed., Pearson Education, Boston, MA, 2007.

Greenwald, A. G., C.G. Carnot, R. Beach, and B. Young, "Increasing voting behavior by asking people if they expect to vote," Journal of Applied Psychology, 1987, 72, 315-318.

Harris, J., "Challenges to the Commercial Viability of Point-of-Use (POU) Water Treatment Systems in Low-Income Settings," Oxford University School of Geography and the Environment, 2005.

Hutton, G. and L. Haller, "Evaluation of the Costs and Benefits of Water and Sanitation Improvements at the Global Level," in "World Health Organization, Geneva" 2004.

Jalan, Jyotsna and E. Somanathan, "The importance of being informed: Experimental evidence on demand for environmental quality,' Journal of Development Economics, 2008, 87, 14-28.

Jones, Gareth, Richard W. Steketee, Robert E. Black, Zulfiqar A. Bhutta, Saul S. Morris, and the Bellagio Child Survival Study Group, "How many child deaths can we prevent this year?," The Lancet, July 5 2003, 362, 65-71.

Kahneman, Daniel and Amos Tversky, "Prospect Theory: An Analysis of Decision under Risk," Econometrica, 1979, 47 (2), 263-291.

(KARI), Kibos Station Kenya Agricultural Research Institute, "Unpublished data."

Kremer, M., E. Miguel, S. Mullainathan, C. Null, and A. Zwane, “Trickle Down: Chlorine Dispensers and Household Water Treatment," working paper, 2009.

, J. Leino, E. Miguel, and A. Zwane, "Spring Cleaning: A Randomized Evaluation of Source Water Quality Improvement," Working paper, 2007, August.

Kremer, Michael and Edward Miguel, “The Illusion of Sustainability," The Quarterly Journal of Economics, 2007, 122(3), 1007-1065.

Lantagne, D.S., "Investigation of the Potters for Peace Colloidal Silver-Impregnated Ceramic Filter: Intrinsic Effectiveness and Field Performance in Rural Nicaragua," Report prepared for USAID, Washington, D.C., 2001.

Luby, S., C. Mendoza, B. Keswick, T. Chiller, and R. Hoekstra, "Difficulties in bringing point-of-use water treatment to scale in rural Guatemala," American Journal of Tropical Medicine and Hygiene, 2008, 78, 382-387. 
, M. Agboatwalla, A. Raza, J. Sobel, E. Mintz, K. Baier, M. Rahbar, S. Qureshi, R. Hassan, F. Ghouri, R.M. Hoekstra, and E. Gangarosa, "A Low-Cost Intervention for Cleaner Drinking Water in Karachi, Pakistan," International Journal of Infectious Diseases, 2001, 5, 144-150.

Madajewicz, M., A. Pfaff, A. van Geen, J. Graziano, I. Hussein, H. Momotaj, R. Sylvi, and H. Ahsan., "Can information alone change behavior? Response to arsenic contamination of groundwater in Bangladesh.," Journal of Development Economics, 2007, 84, 731-754.

Makutsa, P., K. Nzaku, P. Ogutu, P. Barasa, S. Ombeki, A. Mwaki, and R.E. Quick, "Challenges in Implementing a Point-of-Use Water Quality Intervention in Rural Kenya," American Journal of Public Health, 2001, 1 (10), 1571-1573.

Meyerowitz, B. and S. Chaiken, "The effect of message framing on breast self-examination attitudes, intentions, and behavior," Journal of Personality and Social Psychology, March 1987, 52 (3), 500-510.

Mintz, E., J. Bartram, P. Lochery, and M. Wegelin, "Not Just a Drop in the Bucket: Expanding Access to Point-of-Use Water Treatment Systems," American Journal of Public Health, 2001, 91, 1565-1570.

Mirza, Nasrat M., Laura E. Caulfield, Robert E. Black, and William M. Macharla, "Risk Factors for Diarrheal Duration," American Journal of Epidemiology, 1997, 146 (9), 776-785.

O’Donoghue, Ted and Matthew Rabin, “Doing It Now or Later," American Economic Review, 1999, 89, 103-124.

PSI, Population Services International, "Best Practices in Social Marketing Safe Water Solution for Household Water Treatment: Lessons Learned from Population Services International Field Programs," The Social Marketing Plus for Diarrheal Disease Control: Point-of-Use Water Disinfection and Zinc Treatment (POUZN) Project, Abt Associates, Bethesda, MD March 2007.

Quick, R., E. Mintz, J. Sobel, P. Mead, F. Reiff, and R. Tauxe, "A new strategy for waterborne disease prevention," 23rd WEDC Conference Durban, South Africa, 1997, pp. 340-342.

Quick, R.E., A. Kimura, A. Thevos, M. Tembo, I. Shamputa, L. Hutwagner, and E. Mintz, "Diarrhea Prevention Through Household-Level Water Disinfection and Safe Storage in Zambia," American Journal of Tropical Medicine and Hygiene, 2002, 66 (5), 584-589.

Rabin, Matthew, "Psychology and Economics," Journal of Economic Literature, 1998, 36 (March), 11-46.

Rothman, A.J., S.C. Martino, B.T. Bedell, J.B. Detweiler, and P. Salovey, "The Systematic Influence of Gain- and Loss-Framed Messages on Interest in and Use of Different Types of 
Health Behavior," Personality and Social Psychology Bulletin, 1999, 25(11), 1355-1369.

Simonsohn, U., N. Karsson, G. Loewenstein, and D. Ariely, "The tree of experience in the forest of information: Overweighing experienced relative to observed information," Games and Economic Behavior, 2008, 62(1), 263-286.

Smith, J. K., A.S. Gerber, and A. Orlich, "Self-Prophecy Effects and Voter Turnout: An Experimental Replication,” Political Psychology, September 2003, 24 (3), 593-604.

Smith, S.M. and R.E. Petty, "Message Framing and Persuasion: A Message Processing Analysis," Personality and Social Psychology Bulletin, 1996, 22(3), 257-268.

Sunstein, Cass R., “Terrorism and Probability Neglect,” Journal of Risk and Uncertainty, 2003, 26 (2-3), 121-136.

Tversky, Amos and Daniel Kahneman, "The framing of decisions and the psychology of choice," Science, 1981, 211(4481), 453-458.

Webb, Thomas and Paschal Sheeran, "Does Changing Behavioral Intentions Engender Behavior Change? A Meta-Analysis of the Experimental Evidence," Psychological Bulletin, 2006, 132(2), 249-268.

WHO, World Health Organization Guidelines for Drinking Water Quality, 2nd ed., Vol. 3, WHO, Geneva, 1997.

Zwane, Alix and Michael Kremer, "What Works in Fighting Diarrheal Diseases in Developing Countries? A Critical Review," The World Bank Research Observer, 2007, 22, 1-14.

Figure 1: Time-line of Data Collection Activities

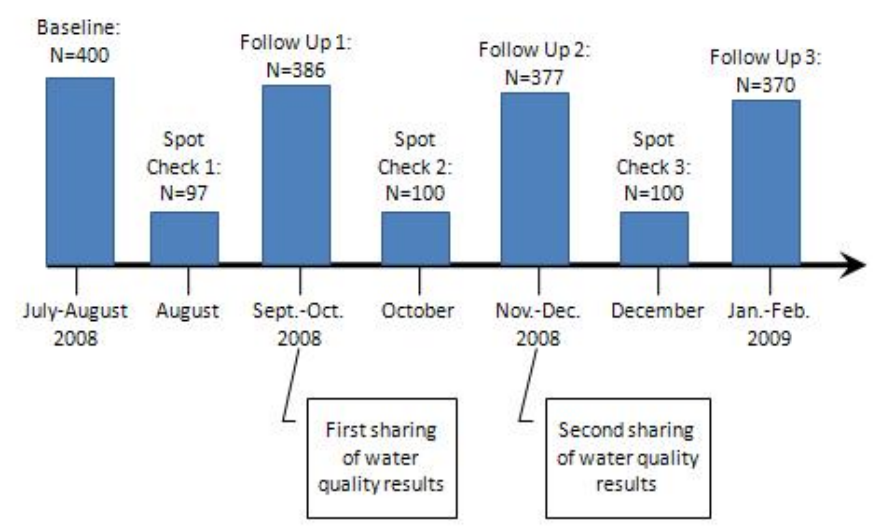


Figure 2: Hypothesized Framing Effects

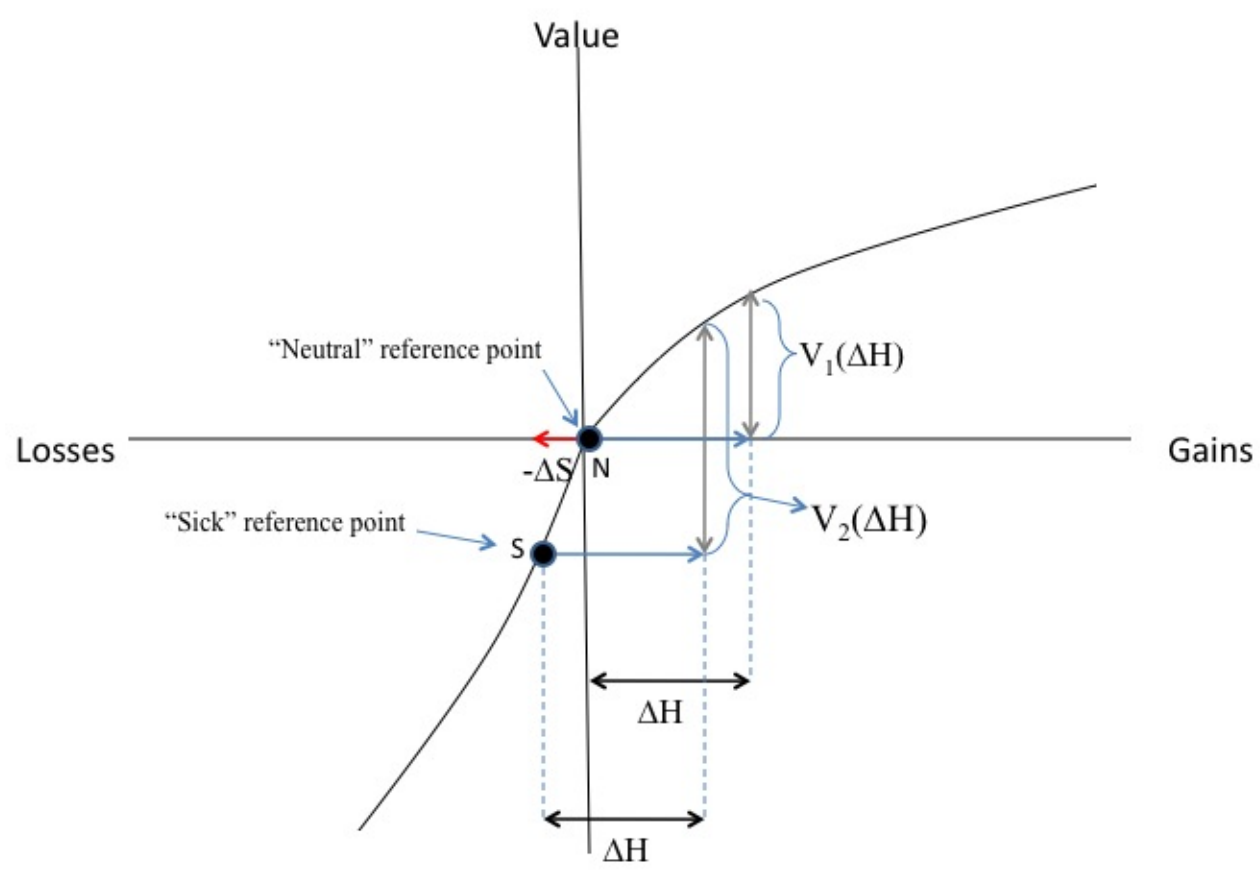

Hypothesized value function of Kahneman and Tversky (1979). $-\triangle S$ represents the "costs" of sickness; $\triangle H$ are the health gains from POU usage; $V_{1}(\triangle H)$ gives the perceived value of health gains under a positively framed message; $V_{2}(\triangle H)$ is the perceived value of health gains under a contrast frame. 
Figure 3: Nonparametric Plots of POU Usage over Time

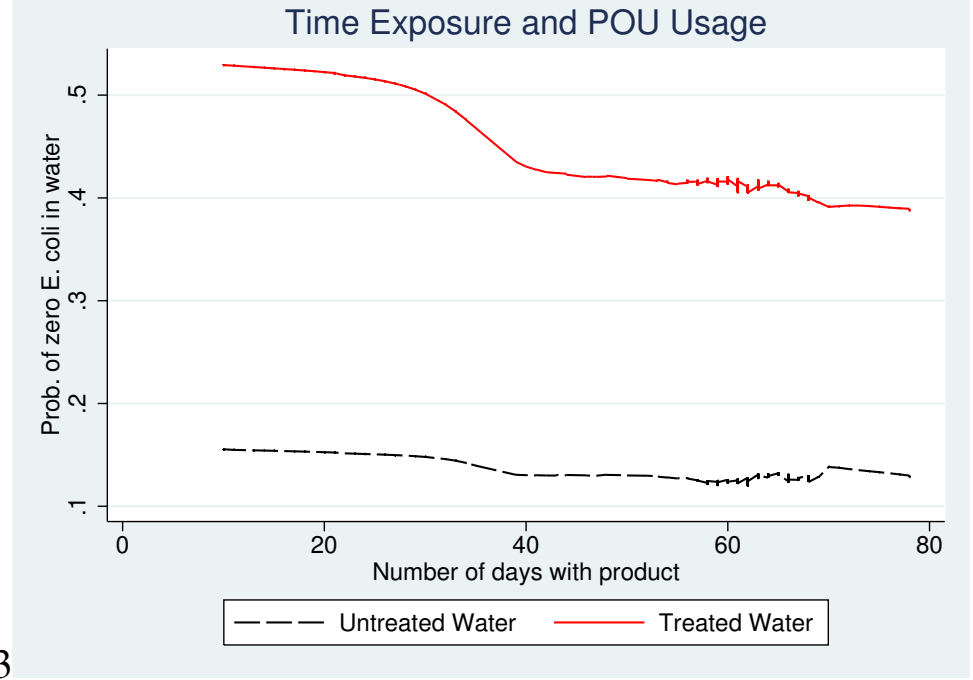

Locally weighted (lowess) regression of the share of homes having treated and untreated water with no detectable $E$. coli over the number of days with a product (count). The number of days with a product combines data from spot check and full follow-up survey rounds. There are more observations around 60 days. Bandwidth $=1$.

Figure 4: Nonparametric Framing Effects Over Time

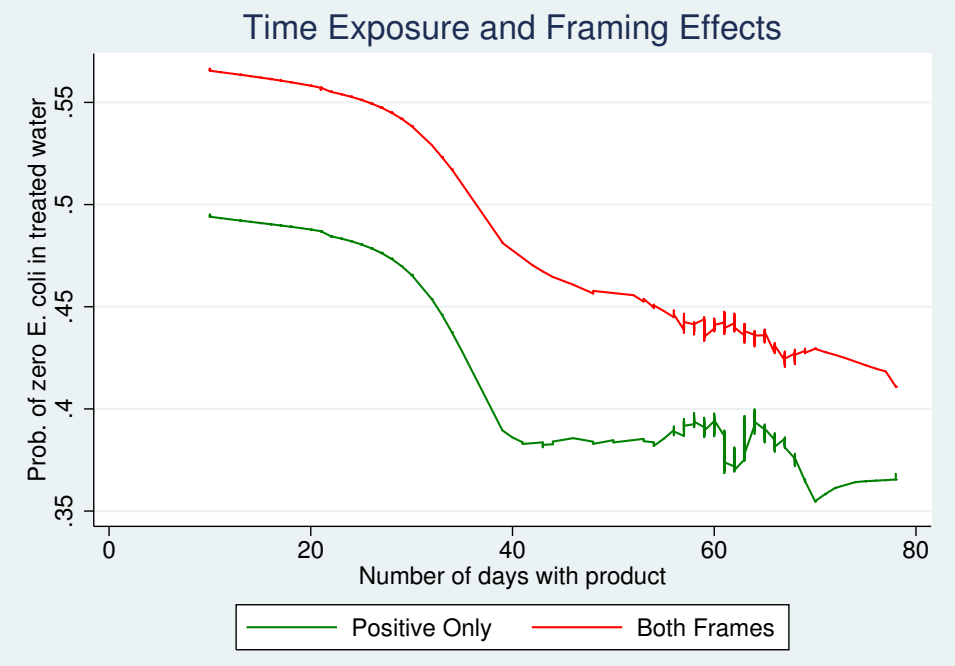

Locally weighted (lowess) regression of POU usage indicator (defined as having zero E. coli in treated water) over the number of days with a product (count). The number of days with a product combines data from all spot check rounds with full follow-up survey rounds which means there are more observations around 60 days. Bandwidth $=1$. 
Figure 5: Within-Wave Relative Usage by Information Received

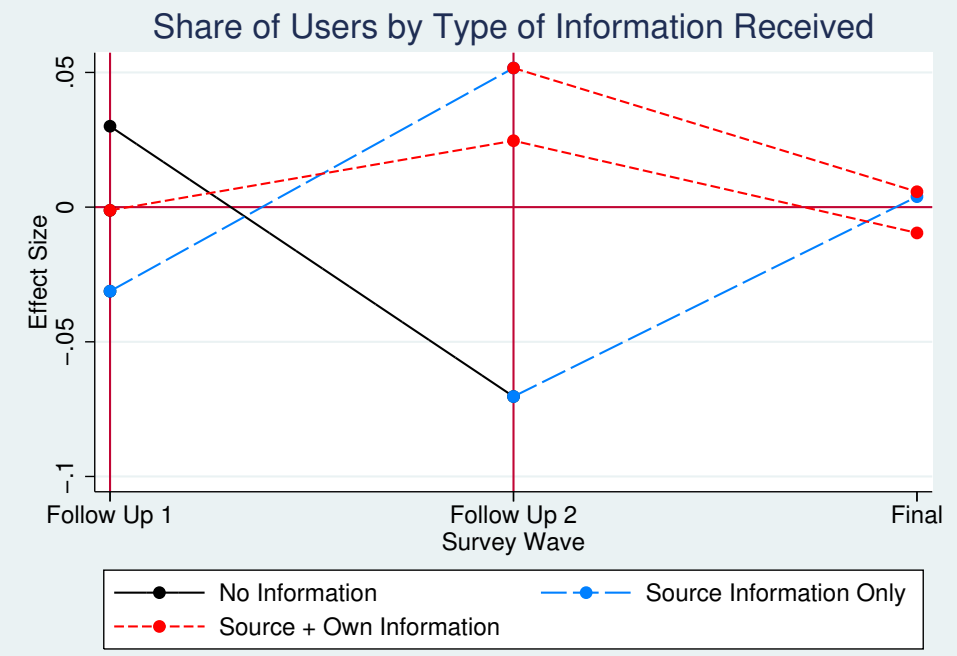

The two vertical lines represent introduction of new information treatments at follow-up 1 and follow-up 2 waves. "Effect Size" refers to relative share of total users within one wave from each of the three information treatment groups. Usage is defined as a household's treated water having an E. coli MPN $<10 \mathrm{CFU} / 100 \mathrm{~mL}$. All data have been time de-meaned, so relevant comparisons are always across information groups within a time period, i.e., comparisons of overall usage across survey waves are not valid. 
Table 1: Summary Baseline Means

\begin{tabular}{|c|c|c|c|}
\hline Baseline Water Quality Variables & Obs & Mean & S.D. \\
\hline E. coli MPN (Count of E. coli $\mathrm{CFU} / 100 \mathrm{~mL}$ in stored water) & 377 & 155.705 & 413.148 \\
\hline "Zero Risk" (No E. coli in stored water) & 377 & 0.135 & 0.342 \\
\hline "Low Risk" (E. coli MPN < 10 CFU/100 mL) & 377 & 0.403 & 0.491 \\
\hline "Intermediate Risk" (10 CFU/100 mL < E. coli MPN < 100 CFU/100 mL) & 377 & 0.679 & 0.467 \\
\hline "High Risk" (E. coli > 100 CFU/100 mL) & 377 & 0.186 & 0.389 \\
\hline "Very High Risk" (E. coli > 1000 CFU/100 mL) & 377 & 0.053 & 0.224 \\
\hline \multicolumn{4}{|l|}{ Baseline Water and Hygiene } \\
\hline Soap present in home during interview & 400 & 0.463 & 0.499 \\
\hline HH reports child $<5$ had diarrhea in past two weeks & 400 & 0.423 & 0.495 \\
\hline HH reports losing a child & 400 & 0.335 & 0.473 \\
\hline Main water source is tap water & 400 & 0.433 & 0.496 \\
\hline Current water source is tap water & 400 & 0.303 & 0.460 \\
\hline Main water source is rain water & 400 & 0.078 & 0.268 \\
\hline Current water source is rain water & 400 & 0.543 & 0.499 \\
\hline Main water source is earthpan & 400 & 0.360 & 0.481 \\
\hline Current water source is earthpan & 400 & 0.113 & 0.316 \\
\hline Main water source is river & 400 & 0.095 & 0.294 \\
\hline Current water source is river & 400 & 0.025 & 0.156 \\
\hline \multicolumn{4}{|l|}{ Baseline Respondent/HH Characteristics } \\
\hline Female respondent & 400 & 0.885 & 0.319 \\
\hline Married, with only 1 spouse & 400 & 0.715 & 0.452 \\
\hline Household size & 400 & 5.935 & 2.326 \\
\hline No. of additional "occasional" drinkers from HH's pot & 400 & 2.825 & 3.082 \\
\hline Some secondary education or above & 400 & 0.183 & 0.387 \\
\hline Illiterate adult respondent & 400 & 0.113 & 0.316 \\
\hline HH reports farming as main income source & 400 & 0.525 & 0.500 \\
\hline HH prefers 50 Ksh today vs. 100 Ksh in 1 week & 400 & 0.318 & 0.466 \\
\hline HH reports talking with neighbors about water and health & 400 & 0.323 & 0.468 \\
\hline \multicolumn{4}{|l|}{ Baseline Wealth Indicators } \\
\hline Iron roof indicator & 400 & 0.625 & 0.485 \\
\hline $\mathrm{HH}$ has a latrine or toilet structure & 400 & 0.700 & 0.459 \\
\hline $\mathrm{HH}$ owns a radio & 400 & 0.825 & 0.380 \\
\hline Liquidity constrained & 400 & 0.588 & 0.493 \\
\hline \multicolumn{4}{|l|}{ Baseline POU Knowledge and Experience } \\
\hline Diarrhea Knowledge Index (DKI) & 400 & 4.470 & 3.451 \\
\hline HH has heard of WaterGuard & 400 & 0.983 & 0.131 \\
\hline HH has heard of Pur & 400 & 0.893 & 0.310 \\
\hline HH has heard of filter & 400 & 0.360 & 0.481 \\
\hline HH has used WaterGuard previously & 400 & 0.450 & 0.498 \\
\hline HH has used Pur previously & 400 & 0.405 & 0.492 \\
\hline HH has used filter previously & 400 & 0.008 & 0.086 \\
\hline HH has purchased WaterGuard previously & 400 & 0.403 & 0.491 \\
\hline HH has purchased Pur previously & 400 & 0.175 & 0.380 \\
\hline HH reports always boiling their water & 400 & 0.178 & 0.383 \\
\hline
\end{tabular}

23 households had no stored drinking water on hand at baseline. DKI counts the number of valid responses to the question of ways to prevent diarrhea (more details in text). Liquidity constrained households are defined as finding it "very difficult" or "impossible" to get 500 Kenyan shillings ( $\$ 6.25$ as of July 2009) by tomorrow. 
Table 2: Usage Rates Across Products and Definitions

\begin{tabular}{lccccc}
\hline \hline & $(1)$ & $(2)$ & $(3)$ & $(4)$ & $(5)$ \\
\hline \multirow{4}{*}{ Baseline } & Zero E. coli & $\mathrm{T}<10$ & $\mathrm{~T}=0, \mathrm{U}>0$ & Self-Report & Ln E. coli \\
\multirow{3}{*}{ WaterGuard } & 0.128 & 0.380 & & 0.073 & 2.719 \\
& $(0.02)$ & $(0.02)$ & & $(0.01)$ & $(0.12)$ \\
Pur & 0.508 & 0.652 & 0.547 & 0.774 & 0.908 \\
& $(0.03)$ & $(0.02)$ & $(0.03)$ & $(0.02)$ & $(0.14)$ \\
Filter & 0.334 & 0.468 & 0.429 & 0.618 & 1.474 \\
& $(0.02)$ & $(0.03)$ & $(0.03)$ & $(0.02)$ & $(0.14)$ \\
All Products & 0.387 & 0.589 & 0.414 & 0.753 & 1.335 \\
& $(0.03)$ & $(0.03)$ & $(0.03)$ & $(0.02)$ & $(0.14)$ \\
Post-Baseline Obs & 0.410 & 0.569 & 0.463 & 0.715 & 1.241 \\
\hline \hline
\end{tabular}

Spot checks omitted. Standard errors in parentheses clustered at household. Column 1 defines usage as treated water with no detectable E. coli; column 2 indicates share of homes with treated water E. coli MPN $<10 \mathrm{CFU} / 100 \mathrm{~mL}$. Column 3 restricts sample to those households that have both untreated and treated samples on hand, and defines usage as untreated water testing positive for E. coli and treated water testing negative. Column 4 defines usage as self-reporting treatment: current water is treated, treatment was in the past 7 days, and household reports use of POU product every time water is collected. Column 5 is a continuous measure of usage that calculates the $\log$ of E. coli in "drinking water" (treated water if present, else untreated water). More negative values imply more intense usage with this definition. 


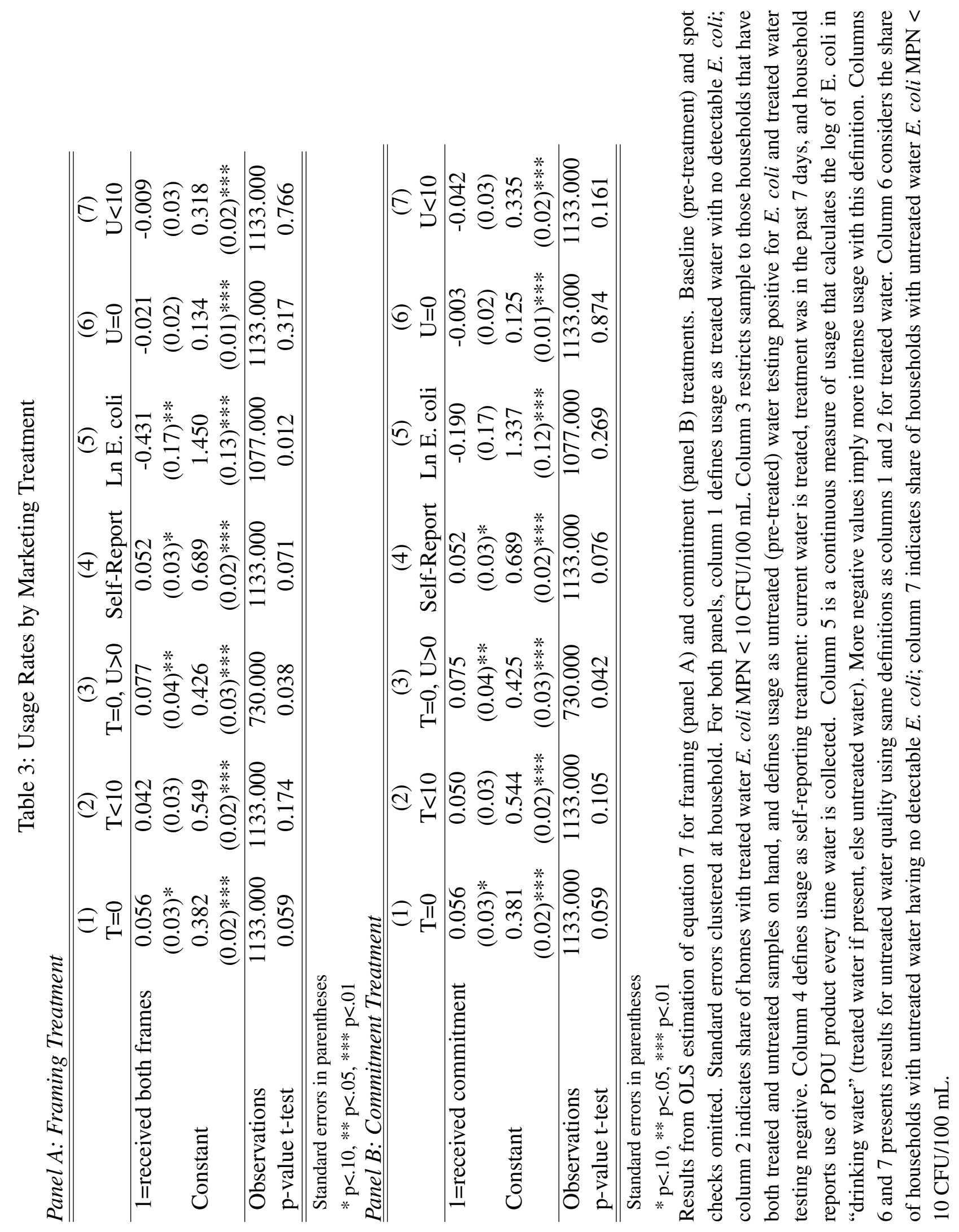


Table 4: Mean Rates of Usage: "Patient" and "Present-Biased" Homes

\begin{tabular}{lcccc}
\hline & $(1)$ & $(2)$ & $(3)$ & $(4)$ \\
\hline & Zero E. coli & Zero E. coli & Ln E. coli & Ln E. coli \\
\hline & Patient & $\begin{array}{c}\text { Present- } \\
\text { Biased }\end{array}$ & Patient & $\begin{array}{c}\text { Present- } \\
\text { Biased }\end{array}$ \\
\hline \hline Control Homes & 0.392 & 0.353 & 1.313 & 1.4 \\
& $(0.03)$ & $(0.04)$ & $(0.15)$ & $(0.24)$ \\
Commitment Treated Homes & 0.418 & 0.475 & 1.324 & 0.811 \\
& $(0.03)$ & $(0.04)$ & $(0.15)$ & $(0.19)$ \\
\hline Difference & 0.026 & $0.122^{* *}$ & 0.011 & $-0.589^{*}$ \\
& $(0.04)$ & $(0.05)$ & $(0.21)$ & $(0.30)$ \\
p-value t-test & 0.478 & 0.0225 & 0.958 & 0.0542 \\
Observations & 779 & 354 & 742 & 335 \\
\hline
\end{tabular}

${ }^{*} \mathrm{p}<.10, * * \mathrm{p}<.05, * * * \mathrm{p}<.01$

Baseline (pre-treatment) and spot checks omitted. Standard errors in parentheses clustered at household. Columns 1 and 2 define usage as treated water with no detectable E. coli; dependent variable in columns 3 and 4 is a continuous measure of usage that calculates the $\log$ of E. coli in "drinking water" (treated water if present, else pre-treated water). More negative values imply more intense usage with this definition. Odd numbered columns contain results across commitment treatment for "patient" homes; even numbered columns contain similar results for "present-biased" households, as defined by responses to hypothetical survey question about future payoffs. More details in text. 
Table 5: All Treatments Combined

\begin{tabular}{lcccccc}
\hline \hline & $(1)$ & $(2)$ & $(3)$ & $(4)$ & $(5)$ & $(6)$ \\
& $\mathrm{T}=0$ & $\mathrm{~T}=0$ & $\mathrm{~T}<10$ & Self-Report & Ln E. coli & $\mathrm{U}<10$ \\
\hline 1=received source info & 0.098 & 0.101 & 0.127 & 0.085 & -0.601 & 0.074 \\
& $(0.04)^{* * *}$ & $(0.04)^{* * *}$ & $(0.04)^{* * *}$ & $(0.04)^{* *}$ & $(0.17)^{* * *}$ & $(0.04)^{*}$ \\
1=received own info & -0.010 & 0.017 & -0.015 & -0.054 & -0.114 & -0.015 \\
& $(0.03)$ & $(0.04)$ & $(0.03)$ & $(0.04)$ & $(0.18)$ & $(0.04)$ \\
1=received own info \& 'dirty' & & -0.035 & & & & \\
& & $(0.06)$ & & & & \\
1=received both frames & 0.054 & 0.053 & 0.031 & 0.052 & -0.317 & 0.009 \\
& $(0.03)$ & $(0.03)$ & $(0.03)$ & $(0.03)^{*}$ & $(0.18)^{*}$ & $(0.03)$ \\
1=received commitment & 0.039 & 0.010 & 0.036 & 0.051 & -0.138 & -0.024 \\
& $(0.03)$ & $(0.03)$ & $(0.03)$ & $(0.02)^{* * *}$ & $(0.15)$ & $(0.03)$ \\
Present-biased household & & -0.025 & & & & \\
& & $(0.05)$ & & & & \\
Commit * Present-Biased & & 0.087 & & & & \\
WaterGuard & & $(0.04)^{*}$ & & & & \\
& 0.109 & 0.109 & 0.070 & 0.022 & -0.379 & -0.030 \\
Pur & $(0.04)^{* * *}$ & $(0.04)^{* * *}$ & $(0.03)^{* *}$ & $(0.03)$ & $(0.20)^{*}$ & $(0.03)$ \\
& -0.067 & -0.067 & -0.096 & -0.134 & 0.196 & -0.041 \\
Filter & $(0.03)^{* *}$ & $(0.03)^{* *}$ & $(0.03)^{* * *}$ & $(0.03)^{* * *}$ & $(0.19)$ & $(0.03)$ \\
& 0.388 & 0.395 & 0.592 & 0.714 & 1.023 & 0.394 \\
\hline Observations & $(0.03)^{* * *}$ & $(0.04)^{* * *}$ & $(0.04)^{* * *}$ & $(0.04)^{* * *}$ & $(0.20)^{* * *}$ & $(0.04)^{* * *}$ \\
R-squared & 1430.00 & 1430.00 & 1430.00 & 1133.00 & 1357.00 & 1430.00 \\
\hline \hline
\end{tabular}

Standard errors in parentheses

$* \mathrm{p}<.10, * * \mathrm{p}<.05, * * * \mathrm{p}<.01$

Results from OLS estimation of equation 8 for all treatments combined. Baseline wave omitted. All models include survey wave fixed effects. Robust standard errors clustered at the village. Note this overstates standard errors for framing and commitment marketing treatments that were assigned at the household level. Columns 1 and 2 define usage as treated water with no detectable E. coli; column 3 indicates share of household observations with treated water E. coli MPN $<10 \mathrm{CFU} / 100 \mathrm{~mL}$. Column 4 defines usage as self-reporting treatment: current water is treated, treatment was in the past 7 days, and household reports use of POU product every time water is collected. Column 5 is a continuous measure of usage that calculates the $\log$ of $E$. coli in "drinking water" (treated water if present, else untreated water). More negative values imply more intense usage with this definition. Column 6 presents results for rates of untreated water with $E$. coli MPN $<10 \mathrm{CFU} / 100 \mathrm{~mL}$. Base rates of usage for WaterGuard and Pur are relative to the filter, and all usage rates listed are from the first two-month follow-up survey wave. 


\section{Appendix}

\section{The Three Included POU Products}

A brief introduction to the three included POU products follows.

\section{WaterGuard}

The US Centers for Disease Control and Prevention (CDC), together with the Pan American Health Organization, developed the Safe Water System (SWS) in response to the need for an inexpensive and simple intervention that delivers clean drinking water to the poor in developing countries. The SWS involves three components. One, contaminated water is treated with a sodium hypochlorite solution (marketed as WaterGuard in Kenya). Two, water should be stored in a proper manner to prevent recontamination. This generally means containers with a narrow mouth, lid and spigot, so that people's hands do not come into direct contact with the water. Three, educational and behavior change techniques should be implemented to establish a link between contaminated water and disease, and to encourage improved personal hygiene and water storage practices as well as regular treatment of water. The SWS arguably has been the most widely implemented POU measure in developing countries and the subject of the most randomized controlled studies to establish its efficacy in combating diarrheal illness. These studies largely agree on SWS's ability to reduce overall diarrheal incidence as well as that of children less than five years old (Luby, Agboatwalla, Raza, Sobel, Mintz, Baier, Rahbar, Qureshi, Hassan, Ghouri, Hoekstra and Gangarosa 2001, Crump, Otieno, Slutsker, Keswick, Rosen, Hoekstra, Vulule and Luby 2004, Quick, Kimura, Thevos, Tembo, Shamputa, Hutwagner and Mintz 2002, CDC 2006, Makutsa, Nzaku, Ogutu, Barasa, Ombeki, Mwaki and Quick 2001). Moreover, an overview study of the cost-effectiveness of various interventions found SWS to be the most cost-effective intervention aimed at improving water and sanitation (Hutton and Haller 2004). SWS is also found to be appropriate and effective in a variety of settings with a variety of source water qualities (Mintz, Bartram, Lochery and Wegelin 2001).

To use WaterGuard: Add one capful of solution into $20 \mathrm{~L}$ of water (the standard jerrycan size). If water is turbid, add two capfuls. Stir the water briefly and then let rest for 30 minutes before drinking.

In conjunction with a free bottle of WaterGuard, our study provided 20 L buckets with covers and taps. This was done to prevent recontamination and thereby make this product more directly comparable to the filter, which includes safe storage in its product design. 


\section{Ceramic Filters}

A variety of field studies have documented the efficacy of ceramic water filters in reducing diarrheal incidence in a variety of developing country settings (Clasen, Parra, Boisson and Collin 2005, Lantagne 2001). However, the efficacy of filters has been found to be lessened in settings with turbid source waters because it slows the filtration process (Brown and Sobsey 2006).

There are currently many different styles of ceramic filters designed to treat water at the household level. For this study, we used Stefani ceramic candle-shaped water filters. The filter design consists of two $20 \mathrm{~L}$ buckets stacked one on top of the other. Untreated water is poured into the top bucket, and then gravity causes the water to flow through the Stefani porous ceramic filters into the bottom bucket, which then dispenses cleaned water through a tap. Thus, the use of a filter involves just one step for households, namely, filling it with water.

\section{Pur}

Manufactured by Procter \& Gamble, PUR is a flocculant-disinfectant powder produced in singleuse sachets that cleans $10 \mathrm{~L}$ of water at a time. Since its introduction in 2003, a growing number of field trials have documented its efficacy in cleaning water and reducing diarrheal morbidity in a variety of settings (Crump et al. 2004, Chiller, Mendoz, Lopez, Alvarez, Hoekstra, Keswick and Luby 2006). Pur is particularly effective at cleaning turbid water: Its flocculant powder is capable of turning brown water clear.

The use of PUR involves considerably more steps than the other two POU measures. It functions by adding one sachet of its mix to a bucket containing $10 \mathrm{~L}$ of water and then stirring the water briskly for 5 minutes. Next, 5 more minutes of waiting time are needed to allow the water's impurities to settle. Then, the water should be filtered using a cotton cloth into a separate storage vessel and left to set for 20 minutes until it is clean. Finally, the residual impurities from the filtration process need to be properly disposed of.

Together with a two month supply of Pur, our study provided two buckets with covers, one with a tap for safe storage purposes and the second without a tap to enable the preparation process of Pur. Again, this was done to allow Pur homes to have safe storage and thereby make this product more directly comparable to the filter. 


\section{Water Testing Procedures}

We tested source waters, stored untreated water, and stored treated water for turbidity, E. coli, and free chlorine residual (in treated water samples in which either PUR or Waterguard were used). Turbidity testing was performed using a portable turbidimeter (Model 2100P, Hach Company, Loveland, CO). In heavily contaminated waters, E. coli measurement was conducted using Petrifilm E. coli/Coliform Count Plates (3M, St. Paul, MN). In samples anticipated to have lower (<3000 CFU/100 ml) concentrations, we used the Colilert Quantitray-2000 assay (IDEXX Laboratories, Westbrook, ME). Free chlorine residual was measured using othotolidine (OTO) test kits (ILP/Swimline, Edgewood, NY).

Table A.1: Randomization Cell Sizes

\begin{tabular}{|c|c|c|c|c|c|c|c|c|}
\hline & & & \multicolumn{2}{|c|}{ WaterGuard } & \multicolumn{2}{|c|}{ Pur } & \multicolumn{2}{|c|}{ Filter } \\
\hline & & & Control & Commit & Control & Commit & Control & Commit \\
\hline \multirow{6}{*}{ Follow-Up 1} & \multirow{2}{*}{ No Info } & Positive & 11 & 11 & 11 & 12 & 10 & 13 \\
\hline & & Contrast & 9 & 13 & 12 & 9 & 10 & 12 \\
\hline & \multirow{2}{*}{ Source Info } & Positive & 8 & 12 & 12 & 10 & 13 & 8 \\
\hline & & Contrast & 12 & 8 & 8 & 13 & 10 & 9 \\
\hline & \multirow{2}{*}{ All Info } & Positive & 13 & 10 & 10 & 9 & 9 & 12 \\
\hline & & Contrast & 11 & 12 & 12 & 10 & 11 & 11 \\
\hline \multirow{6}{*}{ Follow-Up 2} & \multirow{2}{*}{ No Info } & Positive & 11 & 12 & 10 & 13 & 11 & 11 \\
\hline & & Contrast & 10 & 12 & 9 & 13 & 11 & 9 \\
\hline & \multirow{2}{*}{ Source Info } & Positive & 12 & 10 & 13 & 8 & 7 & 12 \\
\hline & & Contrast & 10 & 8 & 12 & 8 & 7 & 13 \\
\hline & \multirow{2}{*}{ All Info } & Positive & 8 & 9 & 9 & 12 & 13 & 10 \\
\hline & & Contrast & 11 & 10 & 9 & 12 & 12 & 10 \\
\hline \multirow{6}{*}{ Follow-Up 3} & \multirow{2}{*}{ No Info } & Positive & 10 & 13 & 11 & 11 & 11 & 12 \\
\hline & & Contrast & 10 & 7 & 10 & 12 & 8 & 13 \\
\hline & \multirow{2}{*}{ Source Info } & Positive & 13 & 8 & 7 & 12 & 12 & 10 \\
\hline & & Contrast & 7 & 13 & 10 & 7 & 12 & 8 \\
\hline & \multirow{2}{*}{ All Info } & Positive & 9 & 12 & 13 & 10 & 8 & 9 \\
\hline & & Contrast & 11 & 10 & 11 & 10 & 9 & 11 \\
\hline
\end{tabular}

Post-baseline average cell size is 10.5 household observations. 15 cells have the maximum cell size of 13 households and 6 cells have the minimum cell size of 7 household observations. 
Figure A.1: Positive Frame

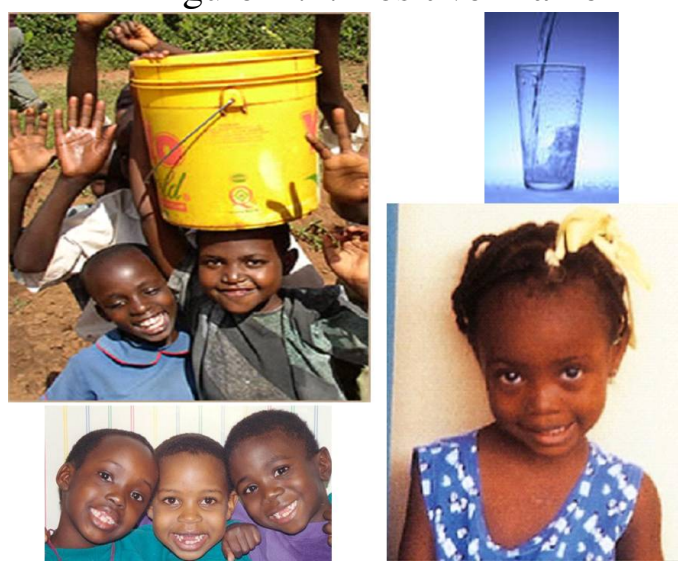

A rough English translation of the corresponding verbal script read aloud to respondents with this set of images is: "By using one of these safe water products, you will be more likely to have clean, safe drinking water, which can help to keep your child[ren] happy and healthy. Use of a safe water product can make it more likely that your days will be healthy, when you can get your important tasks done. And, treating your water makes it more likely that your children will be healthy so they can grow, attend school and learn. A safe water product can help you to achieve a healthier life. A healthier life is a happier life."

Figure A.2: Contrast Frame

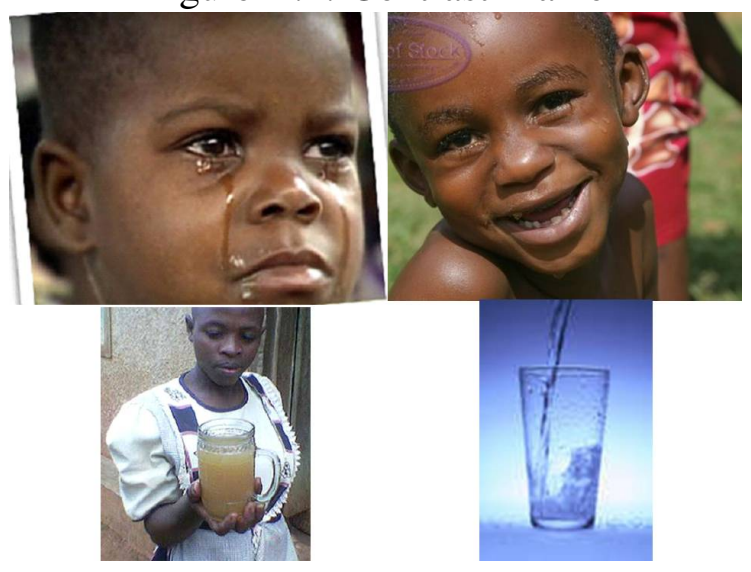

A rough English translation of the corresponding verbal script read aloud to respondents with this set of images is: "Here is a picture of a sad, sick boy from drinking dirty water like we have around here. Here is a picture of a happy, healthy boy. His mother is doing many things to ensure he is having a healthy life and is happy. You also have the strength and the ability to bring such happiness to your children if you provide them with treated water. Use of a safe water product can make it more likely that your days will be healthy, when you can get your important tasks done. And, treating your water makes it more likely that your children will be healthy so they can grow, attend school and learn. A safe water product can help you to achieve a healthier life. A healthier life is a happier life." 
Figure A.3: Baseline Generic Commitment Poster

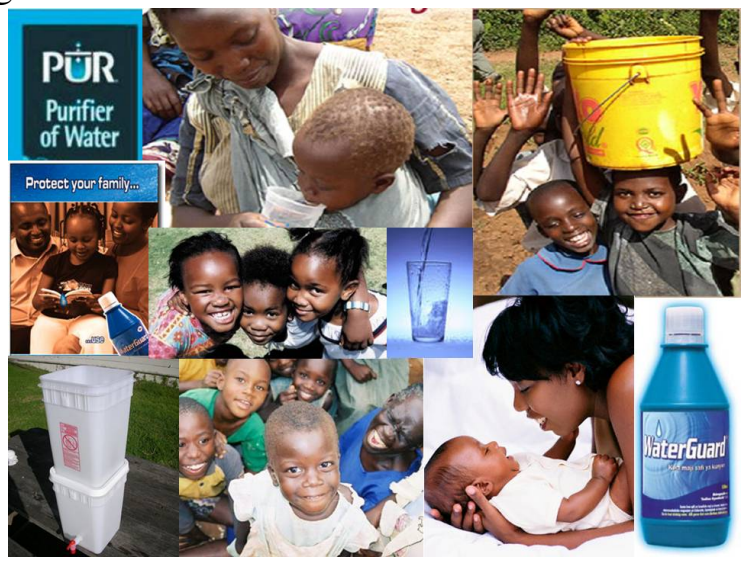

Households assigned to receive the "commitment treatment" were given this poster at the end of the baseline visit. They were also read an additional verbal script whose English translation is: "Before I leave, I would just like to ask you one more thing. You've told me that your child[ren]'s health is important to you and that your child has suffered diarrhea before. Do you want to avoid diarrhea in the future? (WAIT FOR RESPONSE) Do you believe treating your water is important to make it safe to drink? (WAIT FOR RESPONSE) Do you intend to use your safe water product every day for all your children's drinking water to keep them healthy? (WAIT FOR RESPONSE) Will you please say to me, "I will use this safe water product to keep my family's drinking water safe." Finally, as an additional way to remind you to treat your water with your safe water product every day, I'm hoping you will accept this small poster as a gift. Will you hang this poster on the wall in your home to remind you to treat your water every day? Thank you." ENUMERATOR GIVE POSTER TO RESPONDENT.

Figure A.4: Sample Personalized Commitment Poster

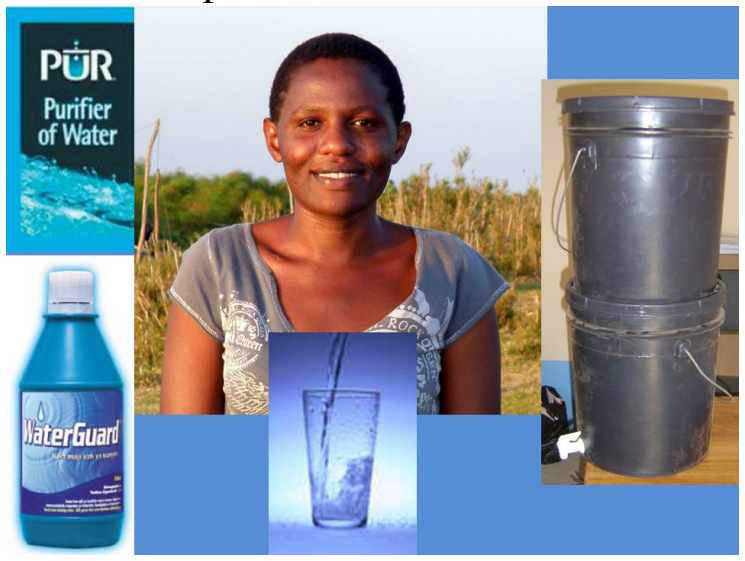

Sample "personalized" commitment poster distributed to households that received "commitment treatment" at follow-up 1 interview. 